\title{
Effect of Phase Contiguity and Morphology on the Evolution of Deformation Texture in Two-Phase Alloys
}

\author{
N.P. GURAO and SATYAM SUWAS
}

Deformation texture evolution in two-phase $x \mathrm{Fe}-y \mathrm{Ni}-(100-x-y) \mathrm{Cr}$ model alloys and Ti-13Nb-13Zr alloy was studied during rolling to develop an understanding of micro-mechanisms of deformation in industrially relevant two-phase FCC-BCC steels and HCP-BCC titanium alloys, respectively. It was found that volume fraction and contiguity of phases lead to systematic changes in texture, while morphology affects the strength of texture. There was a characteristic change in texture from typical Brass-type to a weaker Copper-type texture in the austenite phase accompanied with a change from alpha fiber to gamma fiber in ferrite phase for $\mathrm{Fe}-\mathrm{Ni}-\mathrm{Cr}$ alloys with increase in fraction of harder ferrite phase. However, similar characteristic texture evolution was noted in both $\alpha$ and $\beta$ phase irrespective of the different initial morphologies in Ti-13Nb-13Zr alloy. Viscoplastic self-consistent simulations with two-phase scheme were able to qualitatively predict texture evolution in individual phases. It is proposed that the transition from iso-strain-type behavior for equiaxed microstructure at low strain to iso-stress-type behavior at higher strain is aided by the presence of higher volume fraction of the second phase and increasing aspect ratio of individual phases in two-phase alloys.

DOI: $10.1007 / \mathrm{s} 11661-016-3856-1$

(C) The Minerals, Metals \& Materials Society and ASM International 2016

\section{INTRODUCTION}

MANY engineering alloys like steels, alloys of aluminum, titanium, and zirconium consist of two constituent phases with distinct mechanical and physical properties. It is assumed that the response of two-phase materials to an external stimulus will be an average of the constituent phases. This is, however, not the case and in addition to the properties of individual phases, the response of two-phase materials depends on volume fraction, morphological and crystallographic orientation as well as contiguity of individual phases. The evolution of texture and microstructure during processing of two-phase alloys is of paramount importance in determining the in-service performance of various components. $^{[1-5]}$ This aspect is particularly important for two-phase alloys due to the inherent complexities involved in the deformation of two-phase materials wherein the properties of individual phases interact to decide the overall behavior. Two-phase alloys can be classified into various types depending on the amount and type of the constituent phases. ${ }^{[4]}$ The various possible combinations are an interpenetrating hard/ductile phase or a matrix and inclusion-type microstructure. In addition, in-situ composites like $\mathrm{Cu}-\mathrm{Ag}$. $\mathrm{Cu}-\mathrm{Nb}$ alloys

N.P. GURAO, Assistant Professor, is with the Department of Materials Science and Engineering, Indian Institute of Technology Kanpur, Kanpur 208 016, India. Contact e-mail: npgurao@iitk.ac.in SATYAM SUWAS, Professor, is with the Department of Materials Engineering, Indian Institute of Science, Bangalore 560 012, India.

Manuscript submitted July 10, 2016.

Article published online November 4, 2016 with a ductile eutectic phase and multi-layers of different pure metals and alloys at the nano-length scale constitute special cases of two-phase systems that have been investigated in great detail. ${ }^{[6,7]}$

The mechanism of plastic deformation in two-phase composites is complicated due to the interaction between the two phases. As a general rule, in the presence of a hard and soft phase, it is expected that the softer phase carries more strain, while the harder one takes more stress. Therefore, it may be rationalized that the evolution of deformation texture in the softer phase is accelerated, while that in the harder phase is retarded at a given macroscopic strain compared to the single-phase counterparts. However, the above hypothesis presents an oversimplified scenario during the deformation of two phases and various other microstructural parameters like contiguity, shape, and size as well as crystallographic relationship between the phases influence the texture evolution in the individual phases. The elasto-plastic behavior of such systems has been studied, ${ }^{[2-5]}$ but the large strain plastic deformation has received little attention. Most of the studies have focused on conventional alloys like dual phase mostly ferrite-martensite steels ${ }^{[8-10]}$ and Ti alloys ${ }^{[1-14]}$ as these systems have tremendous industrial applications.

Various investigations ${ }^{[15-26]}$ have employed characterization tools like X-ray, neutron, synchrotron, and electron backscatter diffraction (EBSD) to study texture and microstructure evolution in the individual phases of two-phase materials. Finite element methods and self-consistent simulations ${ }^{[8,13-19]}$ have been used to elucidate the deformation behavior of these materials. Lebensohn et al. ${ }^{[16]}$ modeled the rolling texture 
evolution in two-phase $(\alpha+\beta)$ titanium alloys using a 2-site VPSC formulation that consisted of solving a two inclusion problems as against a single inclusion problem for 1-site VPSC simulations. Titanium $(\alpha+\beta)$ alloys are the classical examples of correlated microstructures with a specific crystallographic orientation relationship between $\alpha$ and $\beta$ phase and the effect of morphology of individual phases still remain unexplored.

In addition, recent investigations have focused on studying deformation of two ductile phases from a fundamental point of view to study slip transfer and coupling of microstructure and texture evolution in individual phases of multi-layers of pure metals at the nano-length scale and in-situ nano-composites. ${ }^{[6,7,27-36]}$ Novel findings like extensive slip and twin transfer, non-crystallographic shear banding, interface amorphous phase formation as well as co-rotation have been found to be relevant in these materials. Thus, technological necessity and a desire to develop fundamental understanding have led to many studies at the extreme length scales. However, fundamental understanding of micro-mechanisms of deformation as developed for multi-layers is still missing for bulk two-phase systems. The effect of contiguity and morphology of individual phases on deformation microstructure and texture evolution has received less attention till date. This is particularly important for two-phase steels and aluminum alloys wherein the volume fraction and contiguity of individual phase play an important role in determining the overall response of the alloy. Similarly, the morphology of the alpha and beta phase plays an important role in titanium alloys with engineering applications. The present investigation aims to explore $x \mathrm{Fe}-y \mathrm{Ni}-(100-x-y) \mathrm{Cr}$ alloys and $\mathrm{Ti}-13 \mathrm{Nb}-13 \mathrm{Zr}$ as model systems to study the effect of contiguity and morphology of the second phase, respectively using electron backscatter and X-ray diffraction as well as crystal plasticity simulations.

\section{EXPERIMENTAL}

\section{A. Materials and Processing}

Four compositions of Fe-Ni-Cr alloys (Table I) were melted using a vacuum arc furnace. Different volume fractions of $\mathrm{BCC}$ ferrite phase were obtained in the $\mathrm{FCC}$ austenite matrix by varying the content of austenite stabilizer $\mathrm{Ni}$ and ferrite stabilizer $\mathrm{Cr}$. The cast structure of the alloys was broken by hot forging at $1373 \mathrm{~K}$ $\left(1100{ }^{\circ} \mathrm{C}\right)$ to 50 pet reduction in thickness. The so-obtained wrought alloys were subjected to long-term annealing as described in Table I to obtain equiaxed microstructures. The composition of the alloys ensured different kinds of microstructures from inclusion-type to interpenetrating network-type in addition to different volume fractions of the harder ferrite phase in the soft austenite matrix. Ti-13Nb-13Zr alloy was prepared by vacuum arc melting. The cast material was hot-rolled at $1173 \mathrm{~K}\left(900{ }^{\circ} \mathrm{C}\right)$ in the $\beta$ phase field to break the as-cast microstructure. Following this, two distinct thermo-mechanical treatments were carried out to obtain two different morphologies: (a) annealing in the $\beta$ field at $1173 \mathrm{~K}\left(900{ }^{\circ} \mathrm{C}\right)$ to obtain a colony microstructure and (b) cold rolling to 50 pct reduction at room temperature followed with annealing at $938 \mathrm{~K}\left(665^{\circ} \mathrm{C}\right)$ for 24 hours to obtain an equiaxed microstructure of $\alpha$ and $\beta$ phase.

Samples with dimensions $15 \times 10 \times 5 \mathrm{~mm}$ were machined from the heat-treated materials and subjected to cold rolling using a Buhler laboratory-scale two high-rolling mills to a final 90 pet reduction $(\varepsilon=2.3)$ for $x \mathrm{Fe}-y \mathrm{Ni}-(100-x-y) \mathrm{Cr}$ alloys, while a reduction of 50 pct $(\varepsilon=0.69)$ and 65 pet $(\varepsilon=1.0)$ for colony and equiaxed microstructures of Ti-13Nb-13Zr alloy, respectively. It is to be mentioned here that Ti-13Nb-13Z samples showed extensive edge cracking beyond aforementioned reduction even for deformation in steps of 5 pet rolling reduction per pass.

\section{B. X-Ray and Electron Back Scatter Diffraction}

Bulk texture measurement using Schulz reflection geometry was carried out using Bruker D8 Discover diffractometer using $\mathrm{Co} \mathrm{K} \alpha$ radiation. Incomplete (111), (200), (220), and (113) pole figures of austenite and incomplete (110), (200), and (112) pole figures of ferrite were measured. Similarly incomplete (0002), (10 $\overline{1} 0)$, $(10 \overline{1} 1),(10 \overline{1} 2),(10 \overline{1} 3),(10 \overline{2} 0)$, and $(10 \overline{2} 2)$ pole figures were measured for the HCP $\alpha$ phase and (200) and (112) incomplete pole figures were measured for the BCC $\beta$ phase in Ti-13Nb-13Zr alloy. Sufficient care was taken to avoid overlapping of peaks during individual pole figure measurement by using a narrow slit and point detector. A detailed analysis of texture was performed by calculating the three-dimensional Orientation Distribution Function (ODF) from the experimental incomplete pole figures by commercially available LaboTex software using the Arbitrary Defined Cells algorithm. ${ }^{[37]}$ Microstructural characterization was carried out using a Field Emission Gun Scanning Electron Microscope (FEG-SEM) Sirion equipped with TSL-OIM Electron Backscatter Diffraction (EBSD) system. TSL-OIM software version 5.2 was used for data acquisition and analysis. Different step sizes were used to capture the microstructural details of the deformed samples. It is to be mentioned here that all X-ray investigations were carried out at the mid thickness of the ND plane, while EBSD was carried out on the center of the TD plane of the rolled samples.

\section{VISCOPLASTIC SELF-CONSISTENT SIMULATIONS}

Crystal plasticity simulations were carried out using the VPSC-7 package including the two-phase sub-routine. The VPSC model is described in detail in Reference 38 and the Predominant Twin Reorientation (PTR) scheme is elaborated in Reference 39. For two-phase materials, a two-site viscoplastic self-consistent model that is an extension of Eshelby problem to two interacting ellipsoidal inclusions was employed. ${ }^{[40]}$ The two-phase model calculates one-site Eshelby tensors 
Table I. Chemical Composition of the Four Different Fe-Ni-Cr Alloys

\begin{tabular}{|c|c|c|c|c|c|}
\hline Alloy & $\mathrm{Ni}$ (Wt Pct) & $\mathrm{Cr}$ (Wt Pct) & $\mathrm{Fe}(\mathrm{Wt}$ Pct) & Ferrite (Pct) & Heat Treatment \\
\hline I & 17 & 21 & 62 & 0 & $1293 \mathrm{~K}\left(1020^{\circ} \mathrm{C}\right)$ for $2 \mathrm{~h}$ \\
\hline II & 15 & 23 & 62 & 15 & $1398 \mathrm{~K}\left(1125^{\circ} \mathrm{C}\right)$ for $12 \mathrm{~h}$ \\
\hline III & 14 & 24 & 62 & 35 & $1448 \mathrm{~K}\left(1175^{\circ} \mathrm{C}\right)$ for $5 \mathrm{~h}$ \\
\hline IV & 10 & 28 & 62 & 65 & $1343 \mathrm{~K}\left(1070{ }^{\circ} \mathrm{C}\right)$ for $12 \mathrm{~h}$ \\
\hline
\end{tabular}

The respective ferrite volume fraction and the heat treatment followed are also presented.

for the individual phases as well as two-site Eshelby tensor for each phase that acts as coupling factors between the eigenstrain in one inclusion and local deviation in strain of other phase. Consider two inclusions (\#1 and \#2) with eigenstrains $\varepsilon^{1 *}$ and $\varepsilon^{2 *}$, respectively, embedded in a matrix subjected to macroscopic stress-strain state $(\Sigma, E)$. The microscopic stress-strain state in both the inclusions will be different and can be given by $\left(\sigma^{1}, \varepsilon^{1}\right)$ and $\left(\sigma^{2}, \varepsilon^{2}\right)$. The stress and strain deviations are as follows:

$$
\begin{aligned}
& \tilde{\sigma}^{1}=\sigma^{1}-\Sigma \\
& \tilde{\sigma}^{2}=\sigma^{2}-\Sigma \\
& \tilde{\varepsilon}^{1}=\varepsilon^{1}-E \\
& \tilde{\varepsilon}^{2}=\varepsilon^{2}-\mathrm{E}
\end{aligned}
$$

and the Eshelby relations are

$$
\begin{aligned}
& \tilde{\varepsilon}^{1}=S^{11} \varepsilon^{1 *}+S^{12} \varepsilon^{2 *} \\
& \tilde{\varepsilon}^{2}=S^{21} \varepsilon^{1 *}+S^{22} \varepsilon^{2 *}
\end{aligned}
$$

where $S^{11}$ and $S^{22}$ are ordinary Eshelby tensors for inclusions \#1 and \#2, respectively, and depend on the properties of the homogeneous medium and shape of ellipsoid. $S^{12}$ and $S^{21}$ represent two-site Eshelby's tensors that act as coupling factors between eigenstrain of one inclusion and local deviation in strain of the other inclusion. The two-phase scheme developed above is then incorporated in conventional viscoplastic self-consistent model. The two-site model can incorporate the volume fraction and morphology of the individual phases as well as crystallographic relationship between the two phases. The measured bulk texture was discretized to obtain 2000 single orientations for individual phases that were used as input to the model. An aspect ratio of one was used for both the phases as the microstructures showed equiaxed grains for both the phases in all four alloys. An intermediate affine-based linearization procedure that gives a response between the iso-stress and iso-strain that constitute the lower and upper bounds was adopted to carry out the simulations.

A similar approach was followed for Ti-13Nb-13Zr, albeit with different aspect ratios of the individual phase as well as two different morphological orientations were considered in the simulations. In addition, it was found that the best match of texture was obtained by adopting the $n^{\text {eff }}=10$ approximation in VPSC-7 code. Thus, the following three sets of simulations were carried out on Ti-13Nb-13Zr alloy:

(i) Aspect ratio and no morphological orientation (ishape $=2$, where ishape is the grain morphology index used in VPSC simulation to calculate the Eshelby's tensor. If ishape $=2$, individual grain ellipsoids are used to calculate Eshelby's tensor).

(ii) Aspect ratio and similar morphological orientation of both the phases, ishape $=4$ (initial grain ellipsoid information is read from a file and used to calculate Eshelby's tensor).

(iii) Aspect ratio and different morphological orientations of individual phases, ishape $=4$

Different morphological orientations were obtained by generating random Euler angles to mimic random orientation of grains in the actual microstructure. Same set of Euler angles was used for both the phases in scheme (ii), while different sets of Euler angles were used for the two phases for scheme (iii).

\section{RESULTS}

\section{A. Microstructural Features of the Starting Materials}

\section{1. $\mathrm{Fe}-\mathrm{Ni}-\mathrm{Cr}$ alloys}

The optical micrographs of the starting materials for the four different $\mathrm{Fe}-\mathrm{Ni}-\mathrm{Cr}$ alloys are shown in Figure 1(a). The single-phase austenite alloy I is characterized by an equiaxed microstructure with numerous recrystallization twins, a common feature in annealed low stacking fault energy (SFE) FCC metals and alloys. The microstructures of the remaining three alloys named as alloys II, III, and IV consists of two phases with 15, 35 , and 65 pct of the ferrite (dark phase) and balance austenite phase, respectively. The austenite phase in these alloys exhibits recrystallization twins, while the ferrite phase is devoid of twins. In addition to the different volume fractions, microstructures of the alloys II, III, and IV represent (i) matrix/inclusion, (ii) percolating microstructure, and (iii) inclusion/matrix-type morphology. Thus, the three alloys correspond to sub-critical, critical, and super-critical percolating system for the ferrite phase. The initial texture of the austenite $(\gamma)$ and ferrite $(\alpha)$ phases in the starting material indicates the presence of Kurdjumov-Sachs 

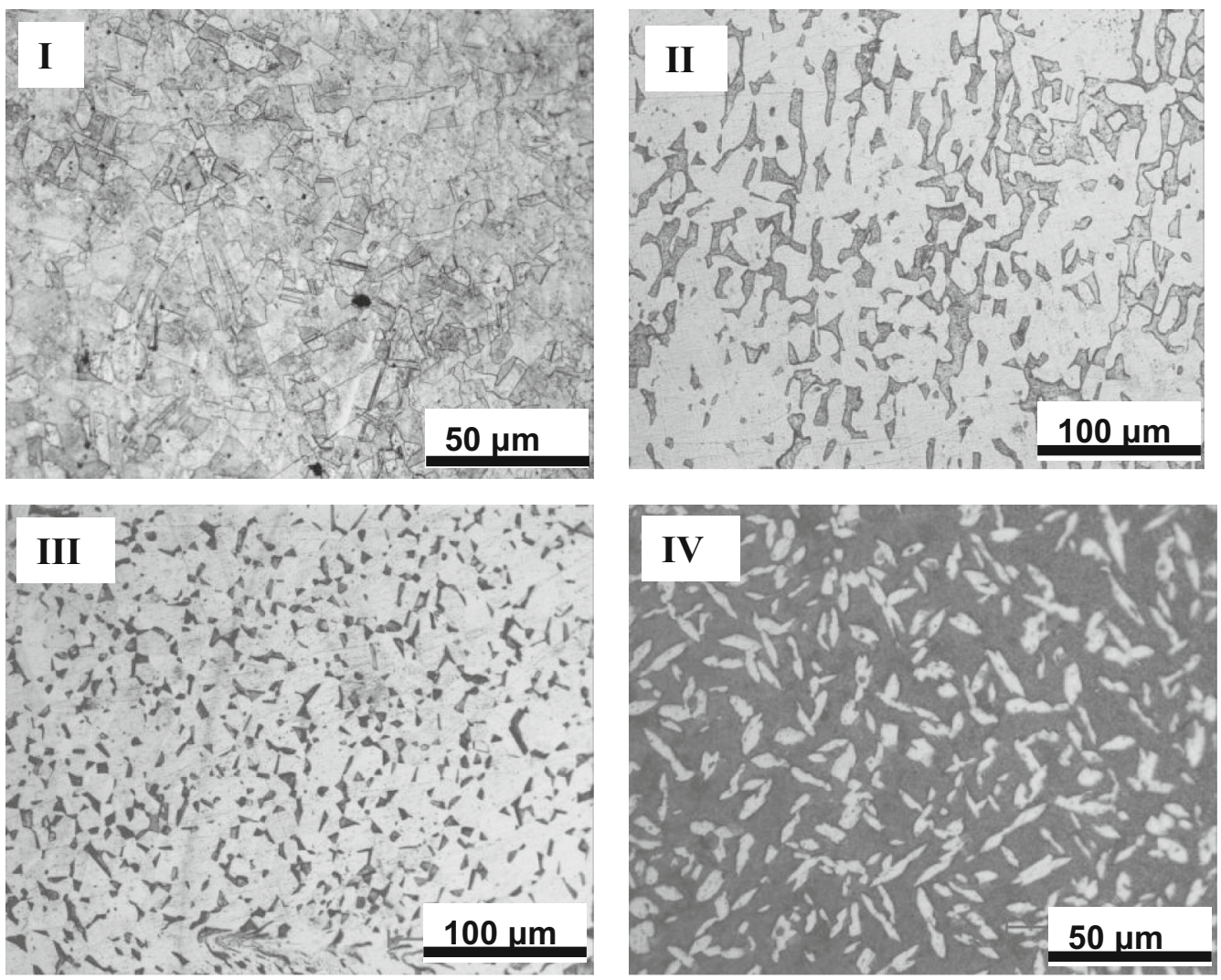

(a)
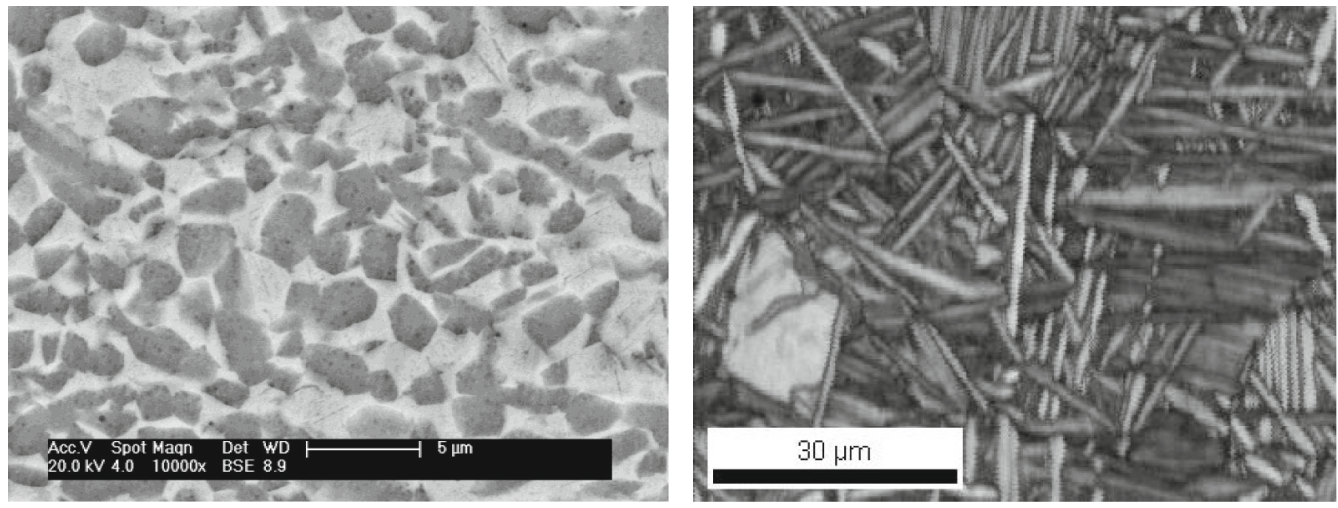

(b)

Fig. 1-(a) Optical micrographs for the starting material of Fe-Ni-Cr alloys and (b) SEM micrograph of equiaxed Ti-13Nb-13Zr sample (left) and image quality map of Ti-13Nb-13Zr sample with colony morphology (right).

orientation relationship ${ }^{[41]}$ wherein $\{111\}_{\gamma} \|\{101\}_{\alpha}$ and $\langle 101\rangle_{\gamma} \|\langle 111\rangle_{\alpha}$ (Figure 2(a)).

\section{Ti-13Nb-13Zr alloy}

The microstructure of the Ti-13Nb-13Zr alloy in two morphologies is shown in Figure 1(b). The material in the $\beta$ worked, cold-worked and recrystallized condition exhibited equiaxed morphology for both $\alpha$ and $\beta$ phases. The microstructure after $\beta$ working and air cooling is characterized by $\alpha$-lath structure in the $\beta$ matrix. The volume fraction of $\alpha$ and $\beta$ phases in the equiaxed microstructure as determined by EBSD was 60 and
40 pct, while that in colony microstructure was 80 and 20 pct, respectively. The pole figures of the two phases indicate the presence of $\{101\}_{\beta} \|\{0002\}_{\alpha}$ and $\langle 111\rangle_{\beta} \|\langle 11 \overline{2} 0\rangle_{\alpha}$ Burgers orientation relationship ${ }^{[42]}$ for Ti-13Nb-13Zr alloy (Figure 2(b)).

\section{B. Evolution of Deformation Texture}

1. The FCC-BCC case: effect of volume fraction and contiguity

The (111) pole figures of $\mathrm{Fe}-\mathrm{Ni}-\mathrm{Cr}$ alloys deformed to the strain level $\varepsilon=2.3$ are shown in Figure 3(a). The 


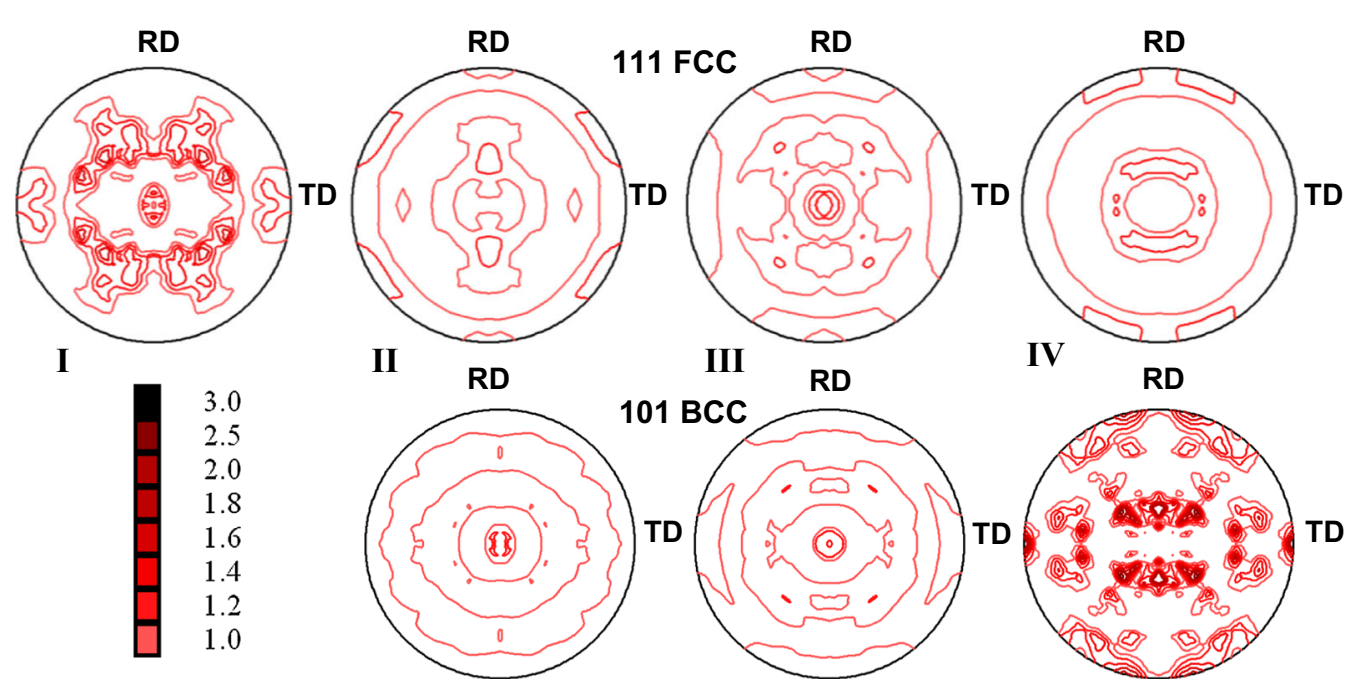

(a)

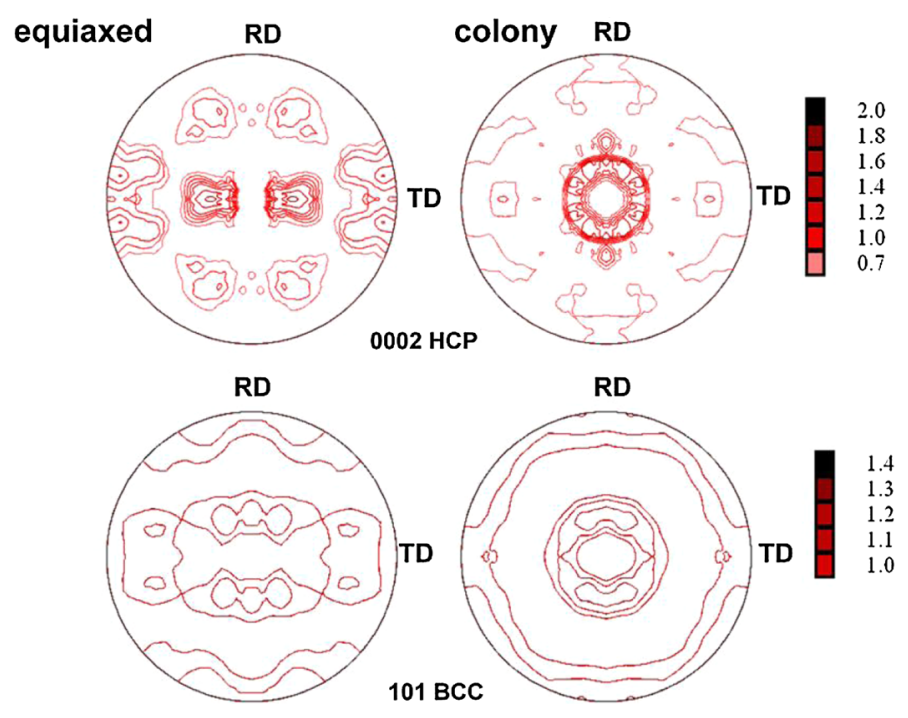

(b)

Fig. 2-(a) Initial texture in terms of (111) pole figure of the austenite phase and (101) pole figure of the ferrite phase for the starting material of $\mathrm{Fe}-\mathrm{Ni}-\mathrm{Cr}$ alloys and $(b)$ initial texture in terms of (0002) pole figure of the $\alpha$ phase and (101) pole figure of the $\beta$ phase for the starting material of Ti-13Nb-13Zr alloy.

pole figure of alloy I displayed a typical Brass-type texture, as exhibited by low SFE FCC materials. Similar evolution of texture was observed in the austenite phase of the other three alloys showing decrease in the texture intensity with increase in ferrite content. The $\varphi_{2}$ sections of the ODF for the samples rolled to the strain level $\varepsilon=2.3$ (Figure 3(b)) corroborated the above observation. The volume fraction of important FCC rolling texture components ${ }^{[1]}$ like Bs $\{1 \overline{1} 0\}\langle 112\rangle, \quad \mathrm{Cu}$ $\{11 \overline{2}\}\langle 111\rangle$, and $S\{12 \overline{3}\}\langle 634\rangle$ reduced as the ferrite content increased. However, a direct comparison of texture by considering the volume fraction of different deformation texture components is not likely to give complete information about the texture evolution in the presence of varying fraction of individual phases. Therefore, the ratio of volume fractions of the individual texture component was obtained (Figure 3(c)) at 50 and 90 pct rolling reduction. The $\mathrm{Cu} / \mathrm{Bs}$ ratio reduced continuously along with $\mathrm{Cu} / \mathrm{S}$ and $\mathrm{S} / \mathrm{Bs}$ ratios with increase in ferrite content. Therefore, it can be inferred that there was an increase in the $\mathrm{Cu}$ component followed by the $\mathrm{S}$ component at the expense of the Bs component with increase in ferrite content.

The (101) pole figures (Figure 4(a)) for the ferrite phase of the three alloys showed a typical BCC rolling texture that strengthened with increase in the ferrite content. The $\varphi_{2}$ sections of the ODF for the ferrite phase of the two-phase samples rolled to the strain level $\varepsilon=2.3$ are shown in Figure 4(b). The important rolling texture components and fibers in BCC metals and alloys, namely, the $\alpha$ fiber ranging from $\{001\}\langle 110\rangle$ to $\{1 \overline{1} 1\}\langle 110\rangle$ and the $\gamma$ fiber ranging from $\{1 \overline{1} 1\}\langle 110\rangle$ to $\{1 \overline{1} 1\}\langle 112\rangle$ are clearly seen in the ODF section. A closer look of the $\operatorname{ODF} \varphi_{2}=45 \mathrm{deg}$ section showed the 
discontinuous nature of the $\alpha$ fiber with higher intensity at orientations close to the $\{001\}\langle 110\rangle$ component for alloy IV.

\section{The HCP-BCC case: effect of morphology}

Figure 5 shows the (0002) pole figures of the deformed samples depicting RD split 0002 pole figure for equiaxed morphology, while a TD split 0002 pole figure was observed for colony microstructure of Ti-13Nb-13Zr alloy. The ODF sections (Figure 6(a)) of the sample with equiaxed morphology showed the presence of characteristic deformation texture components like the $\mathrm{B}\{0001\}\langle 10 \overline{1} 0\rangle$ tilted from ND toward TD component $\left(\varphi_{1}=0, \Phi=40, \varphi_{2}=0\right) \mathrm{deg}$ and the
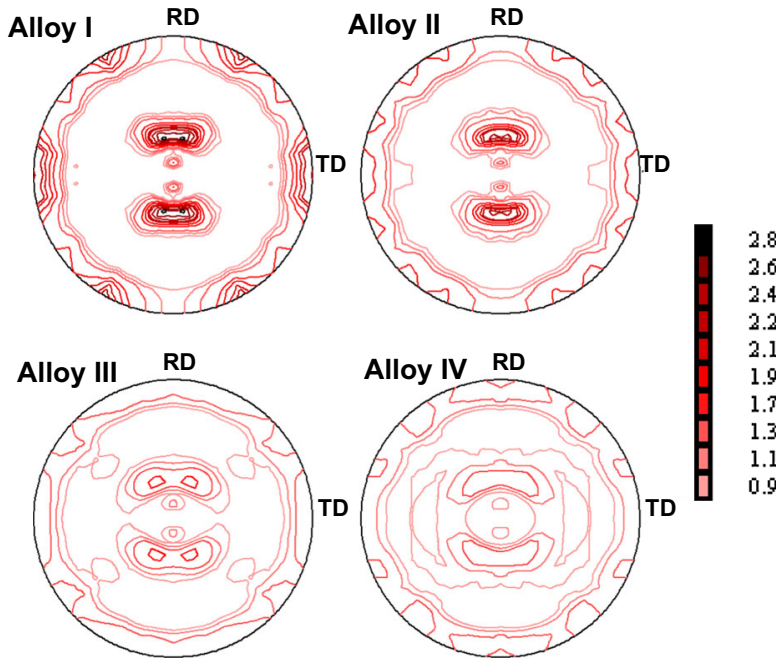

\section{8

(a)
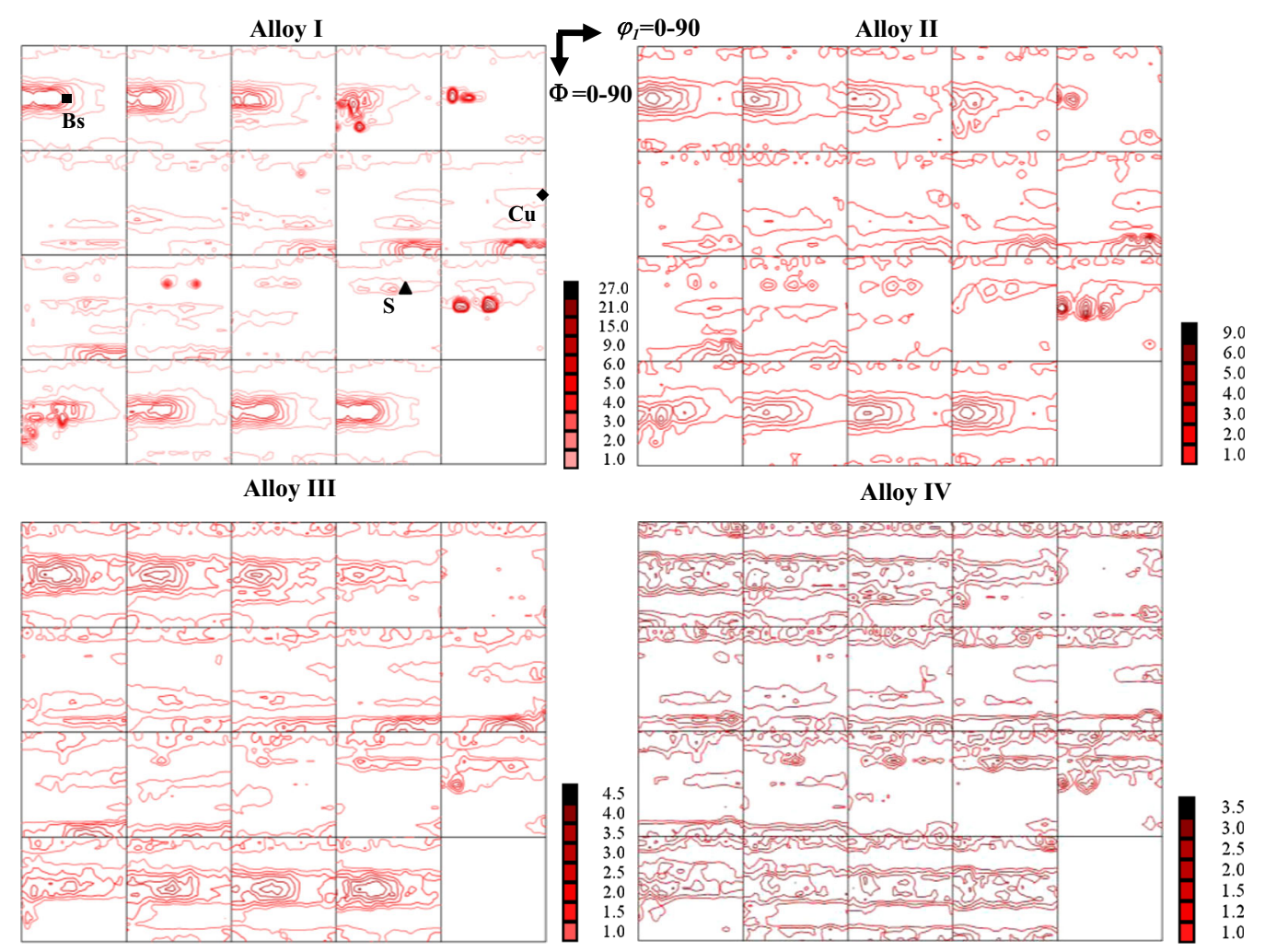

(b)

Fig. 3 - (a) 111 pole figure and $(b) \varphi_{2}$ ODF sections of the austenite phase in the Fe-Ni-Cr samples deformed to strain $\varepsilon=2.3$ and $(c)$ ratio of volume fraction of important deformation texture components in rolled $\mathrm{Fe}-\mathrm{Ni}-\mathrm{Cr}$ alloy in austenite phase. 

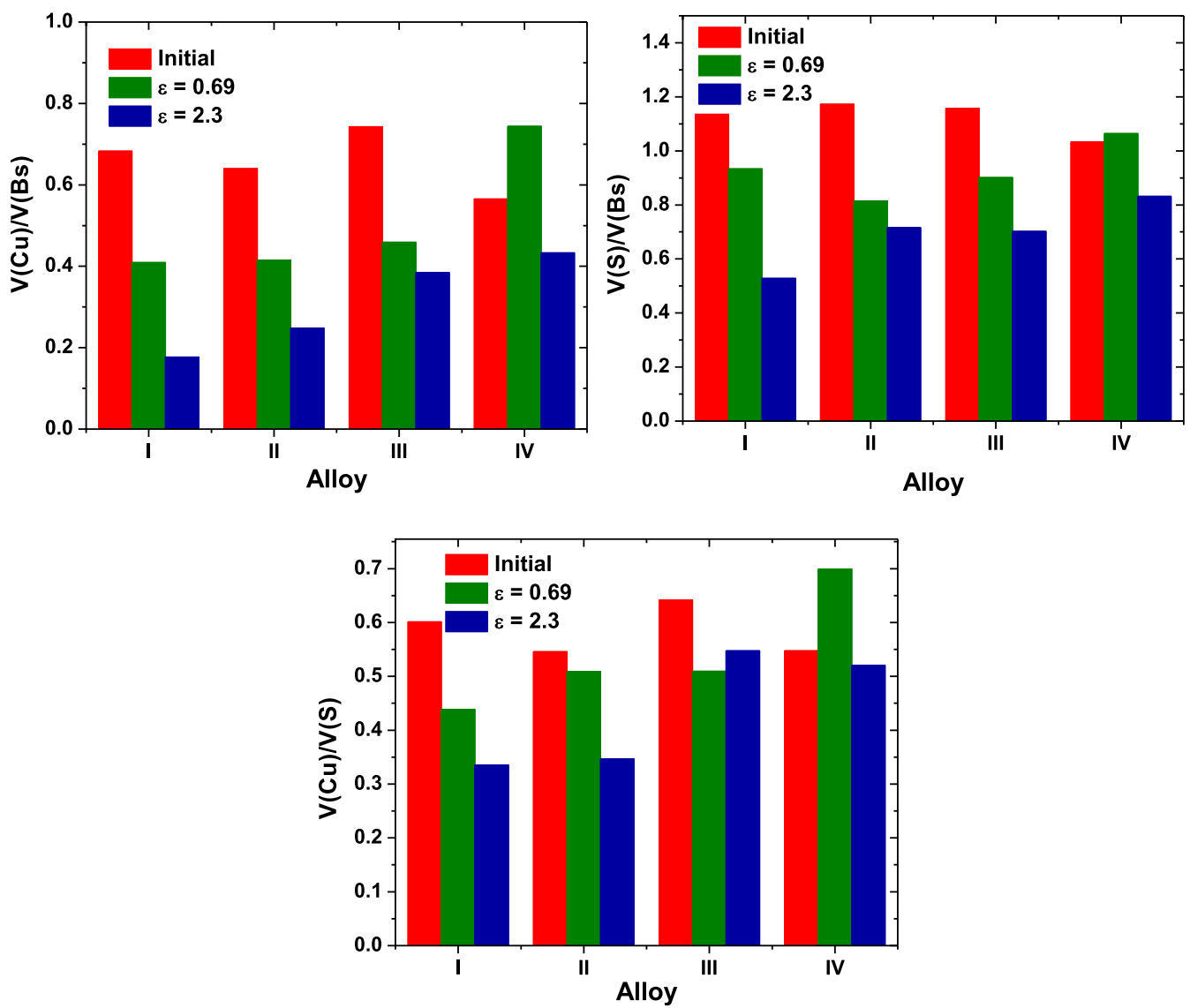

(c)

Fig. 3-continued.

E component $\{0001\}\langle 11 \overline{2} 0\rangle$ tilted from ND toward TD $\left(\varphi_{1}=0, \Phi=40, \varphi_{2}=30\right) \mathrm{deg}$. There is no characteristic change in deformation texture of $\alpha$ phase for both the morphologies; however, the deformation texture of colony morphology becomes stronger with strain, while that for equiaxed weakens at higher strain.

The (101) pole figures for the $\beta$ phase of the deformed samples corresponding to two morphologies of the Ti-13Nb-13Zr alloy are shown in Figure 5. A characteristic rolling texture of BCC metals and alloys is seen in both the cases. The $\varphi_{2}=45 \mathrm{deg}$ section of the ODF (Figure 6(b)) was plotted to get a clearer idea of the texture evolution. The rolling texture of $\beta$ phase was characterized by the presence of $\alpha$ and $\gamma$ fibers. There was an initial increase in the strength of overall texture with deformation that gradually reduced at the highest strain for both the morphologies.

\section{Evolution of Microstructure and Micro-texture}

\section{The FCC-BCC case}

The representative Inverse Pole Figure (IPF) map for the individual phases of the samples rolled to $50 \mathrm{pct}$ reduction (strain $\varepsilon=0.69$ ) shows elongated grains for both the phases (Figure 7(a)). The IPF map of the single-phase austenite alloy (alloy I) displayed extensive twinning. A decrease in the fraction of the twin-boundary fraction is observed with increase in fraction of ferrite. The austenite phase in alloy I and ferrite phase in alloy IV showed gradual conversion of low-angle grain boundaries (LAGB) to high-angle grain boundaries (HAGB) with increase in strain, while the austenite phase in alloy IV showed a monotonic increase in LAGB. The EBSD data also revealed that the intragranular misorientation analyzed in terms of the Grain Average Misorientation (GAM) increased with the deformation for both the phases (Table II) till $50 \mathrm{pct}$ rolling reduction and then decreased or saturated. The difference in GAM values between the two phases reduced with increasing strain in a given alloy and similar observation was made for higher fraction of ferrite phase at given strain. The austenite phase was characterized by deformation twinning which became less dominant with increase in ferrite volume fraction in the two-phase alloy systems. The Sigma 3 (60 deg misorientation about $\langle 111\rangle$ axis) twin-boundary fraction calculated from the EBSD maps clearly (Figure 7(b)) show a decrease in twin fraction with increase in strain and ferrite volume fraction in $\mathrm{Fe}-\mathrm{Ni}-\mathrm{Cr}$ alloys.

\section{The HCP-BCC case}

The morphology of both the phases was modified on rolling. Elongated features are clearly seen in both the microstructures (Figure 7(c)). Significant intragranular 

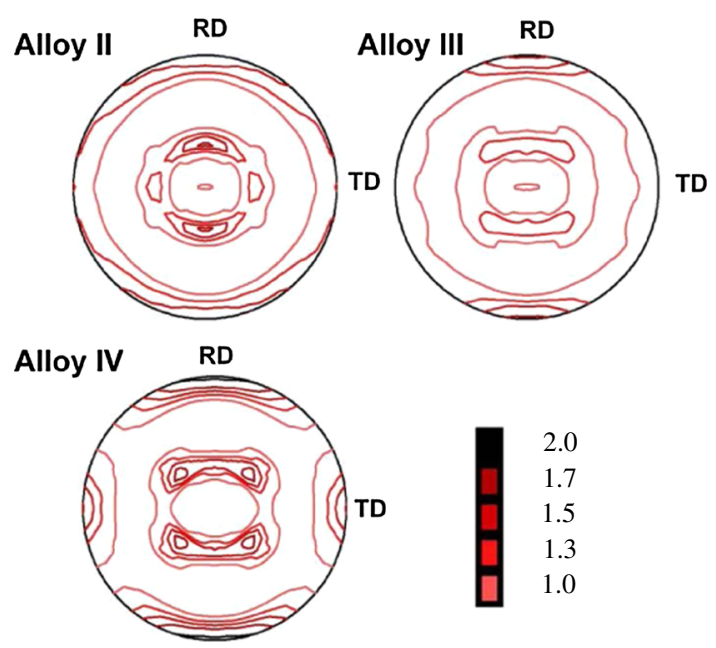

(a)
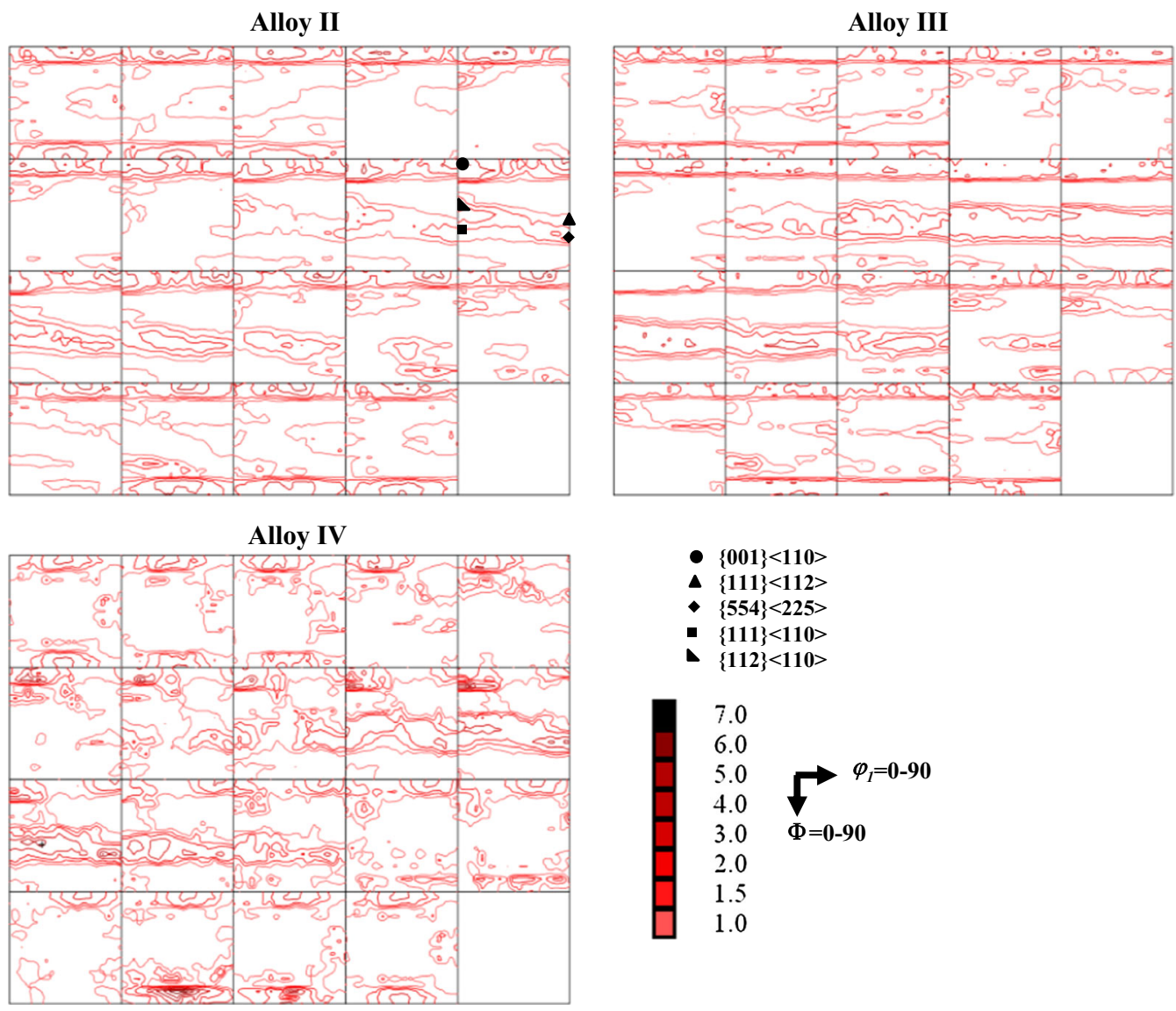

(b)

Fig. 4 - (a) 101 pole figures and $(b) \varphi_{2}$ section of the ODF for the ferrite phase in the three different Fe-Ni-Cr alloys deformed to strain $\varepsilon=2.3$.

misorientation was observed in $\alpha$ phase of the equiaxed as well as colony microstructure. Strong intragranular misorientation developed in the $\alpha$ and $\beta$ phases for both the initial microstructures. This was manifested in terms of the continuous increase in the GAM value with increase in strain. The intragranular misorientation in $\beta$ phase was higher for the colony sample, despite the lower volume fraction compared to the equiaxed microstructure (Table III), while $\alpha$ phase showed higher GAM for equiaxed morphology.

\section{Simulations}

Texture results obtained from viscoplastic self-consistent simulations show a qualitative match with the experimental findings. It is to be mentioned here that the 


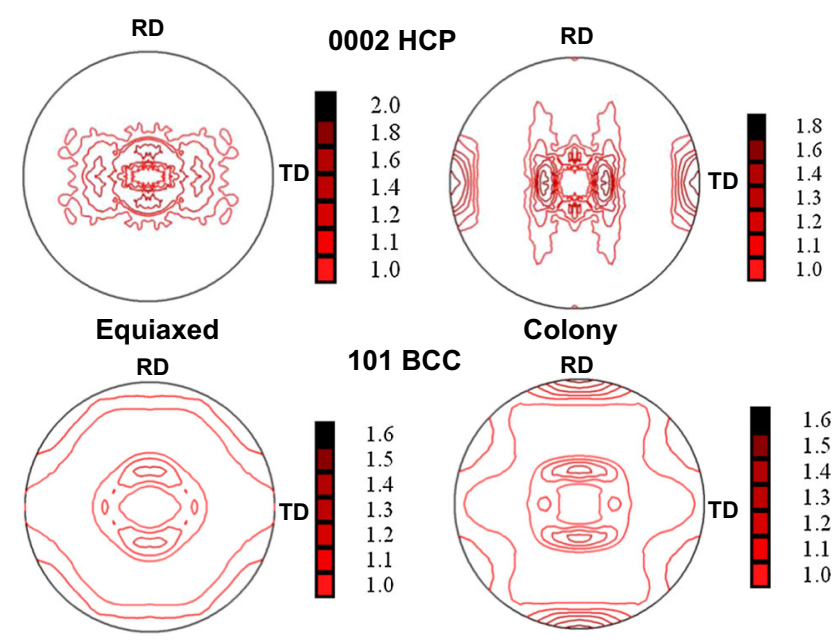

Fig. 5- 0002 pole figures for the $\alpha$ phase and 101 pole figures for the $\beta$ phase of the Ti-13Nb-13Zr alloys in equiaxed and colony morphology at the highest strain of 1 and 0.69 , respectively.

simulation results offer better insight into the operative micro-mechanisms of deformation and are compared with experimental findings like twin fraction, to develop confidence. Detailed results of the simulations are enumerated below.

\section{The FCC-BCC alloys}

The simulated (111) pole figure of the austenite phase and (101) pole figures of ferrite phase of the $\mathrm{Fe}-\mathrm{Ni}-\mathrm{Cr}$ alloys with different austenite contents are presented in Figures 8(a) and (b). The simulated pole figures show a qualitative match with the experimental pole figures for both the phases. The Voce hardening parameters of the austenite and the ferrite phases used for modeling the deformation texture are given in Table IV. Latent hardening coefficient of one was used for slip-slip interaction, while that for slip-twin interaction, a value of 0.9 was used. The pole figures indicated a decrease in Bs component with the increase in ferrite phase. However, the simulated pole figures cannot be directly compared with the experimental pole figures as there is a decrease in the overall intensity of the experimental texture due to X-ray fluorescence. The ratio of volume fraction of the deformation texture components is likely to remain same, for the experimental texture and simulated texture, provided the simulations are appropriate. The simulated $\mathrm{Cu} / \mathrm{Bs}$ ratio for all the four alloys closely matched with the experiments (Figure 3(c)). Thus, there is a gradual deviation from the Brass-type texture in low SFE austenite (alloy I) to Copper-type texture due to the presence of harder ferrite phase.

\section{The HCP-BCC alloy}

Simulations were carried out by activating the prismatic, basal, and pyramidal slip system in the $\alpha$ phase and the $\{110\}\langle 111\rangle$ slip system in the $\beta$ phase. For the equiaxed morphology, an aspect ratio of 1.0:1.0:1.0 was used for both the phases, while for the colony morphology, an aspect ratio of 2.0:1.0:0.5 was used for $\alpha$ phase and an aspect ratio of 2.0:1.0:0.05 was used for the $\beta$ phase. Twinning was not incorporated as a deformation mechanism as the microstructural examination showed that it was not dominant in this alloy. The Voce hardening parameters used for various slip systems in $\alpha$ phase and the $\beta$ phase are given in Table V. Three sets of simulations were carried out by incorporating no morphological information and including two sets of morphological orientation of the individual phases. In one case, random orientations $\left(\varphi_{1} \Phi \varphi_{2}\right)$ were generated for the 2000 orientations of individual phase and incorporated in the simulations. In the latter case, same orientation $\left(\varphi_{1} \Phi \varphi_{2}\right)$ was used for a pair of grains belonging to each phase and incorporated in the simulations. The details of different schemes are given in Table VI. Figures 8(c) and (d) shows the simulated (0002) $\alpha$ pole figures and the (101) $\beta$ pole figures for the rolled Ti-13Nb-13Zr alloy with equiaxed and colony morphology for different schemes. The texture of $\alpha$ phase is qualitatively similar for all the three schemes for equiaxed and colony microstructure. The texture of $\beta$ phase shows better prediction with the experimental texture once the morphology of the individual phase is considered. There is no significant difference between the uncoupled and coupled morphology of both the phases as followed in scheme (ii) and (iii), respectively. However, results from scheme (ii) will be discussed in the subsequent sections as initial texture showed an orientation relationship between the two phases. A reasonable match between the experimental texture and the simulation results by incorporating aspect ratio as well as morphological orientation of individual phase was obtained for both the schemes.

\section{DISCUSSION}

The results of the present investigation indicate a significant role of the second ductile phase on the deformation behavior of two-phase $\mathrm{Fe}-\mathrm{Ni}-\mathrm{Cr}$ and Ti-13Nb-13Zr alloys. The initial textures of the austenite and ferrite phases in the starting material indicate the presence of Kurdjumov-Sachs orientation relationship, ${ }^{[41]}$ while Burgers relationship ${ }^{[42]}$ is valid for $\alpha$ and $\beta$ phases of $\mathrm{Ti}-13 \mathrm{Nb}-13 \mathrm{Zr}$ alloy. However, there is a deviation from the individual relationship with deformation and the orientation relationship is practically non-existent in the heavily rolled samples. Therefore, the two-phase alloys in the present investigation do not deform by co-rotation of individual phases. Nevertheless, elasto-plastic properties, volume fraction, contiguity, and morphological orientation of the individual phases play an important role in the evolution of microstructure and texture by controlling strain partitioning in the individual phases and are discussed below.

\section{A. Influence of Strain Partitioning on Two-Phase Deformation}

The evolution of crystallographic texture and microstructure of individual phases is directly linked to the strain partitioning between the individual phases. 


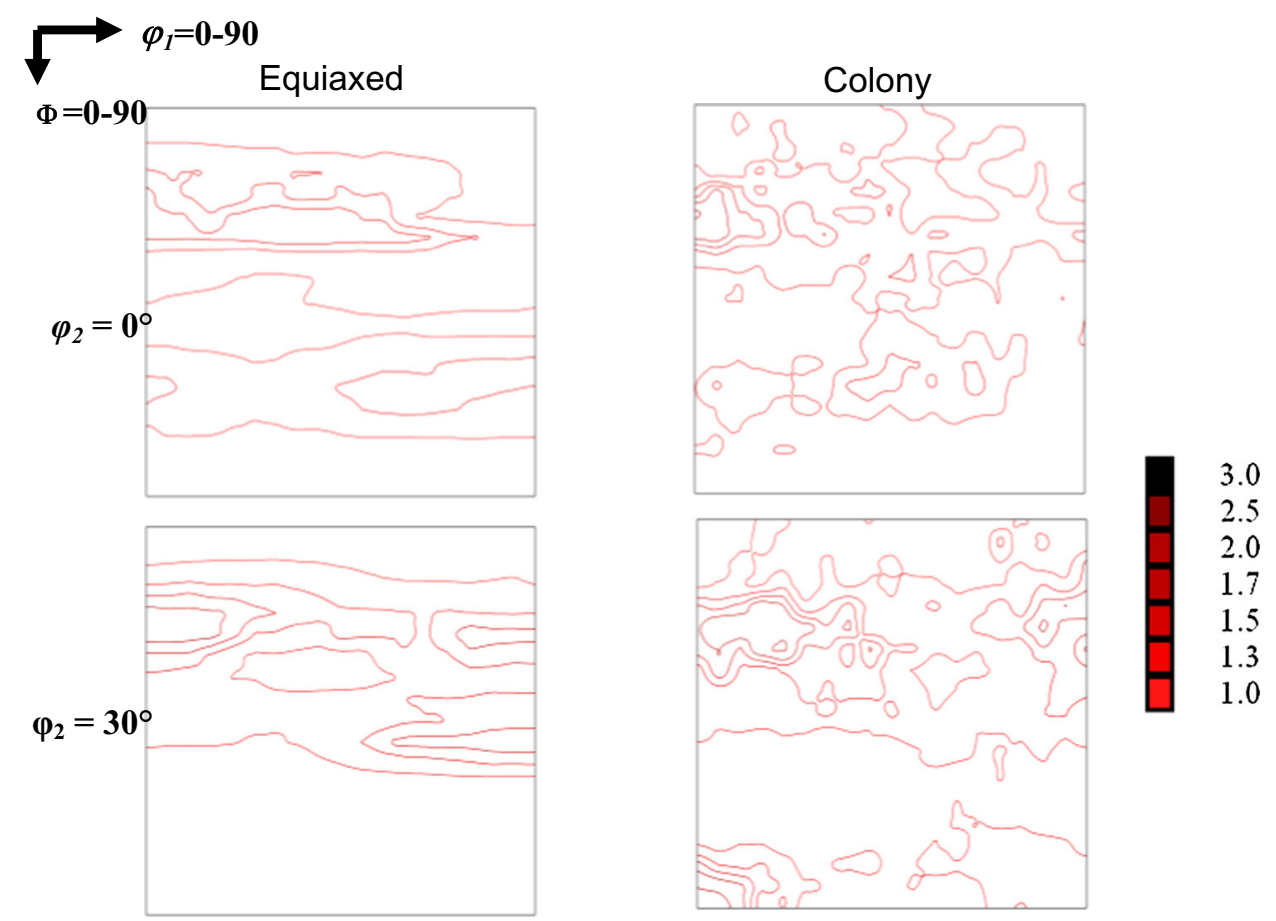

(a)

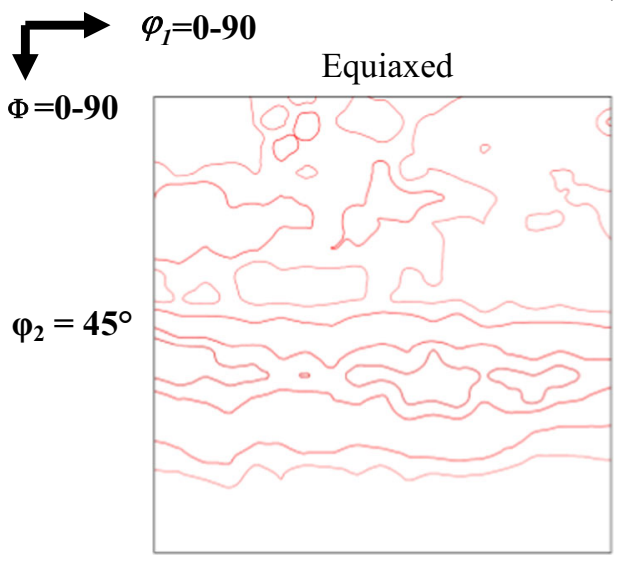

Colony

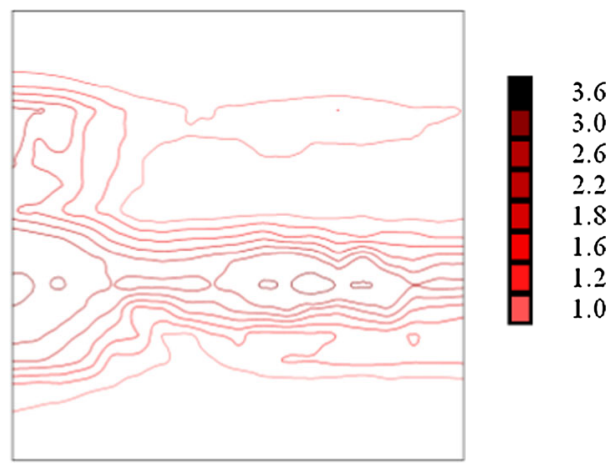

(b)

Fig. 6 - ODF sections for $(a) \alpha$ and $(b) \beta$ phase of the Ti-13Nb-13Zr alloys in equiaxed and colony morphology at the highest strain of 1 and 0.69 , respectively.

For both the alloy systems, the constituent phases have different initial strengths; however, the extent of strain hardening is lower for the softer $\beta$ phase in Ti-13Nb-13Zr compared to softer austenite phase in $x \mathrm{Fe}-y \mathrm{Ni}-(100-x-y) \mathrm{Cr}$ alloys. Strain partitioning can be estimated from the evolution of intragranular misorientation in individual phases. Thus, the results of the present investigation indicate that the softer austenite phase carries most of the strain in $x \mathrm{Fe}-y \mathrm{Ni}-(100-x-y) \mathrm{Cr}$ alloys at different strain levels, similar to softer $\beta$ phase in colony Ti-13Nb-13Zr, while the harder $\alpha$ phase carries more strain in equiaxed morphology. During initial stages of deformation, the softer phase carries most of the strain and undergoes strain hardening and a stage is reached at high plastic strains that the strength of the softer phase becomes comparable to that of harder phase. This is manifested in terms of higher misorientation development in the harder ferrite phase in $x \mathrm{Fe}-y$ $\mathrm{Ni}-(100-x-y) \mathrm{Cr}$ alloys at higher strain and $\alpha$ phase in equiaxed $\mathrm{Ti}-13 \mathrm{Nb}-13 \mathrm{Zr}$ alloy. Thus, an iso-stress condition is achieved in the moderately deformed two-phase microstructure which is manifested in terms of the so-called bamboo structure of elongated grains of both the phases in rolling direction. Experimental observations indicate that the alignment of both the phases is very dominant for all the $x \mathrm{Fe}-y \mathrm{Ni}-(100-x-y) \mathrm{Cr}$ alloys and Ti-13Nb-13Zr alloy with equiaxed morphology. For Ti-13Nb-13Zr alloy with colony morphology, the alignment is not complete which can explain the lack of ductility for this morphology. Thus, there is a deviation from general assumption of softer phase carrying more strain and the real situation is closer to iso-stress 


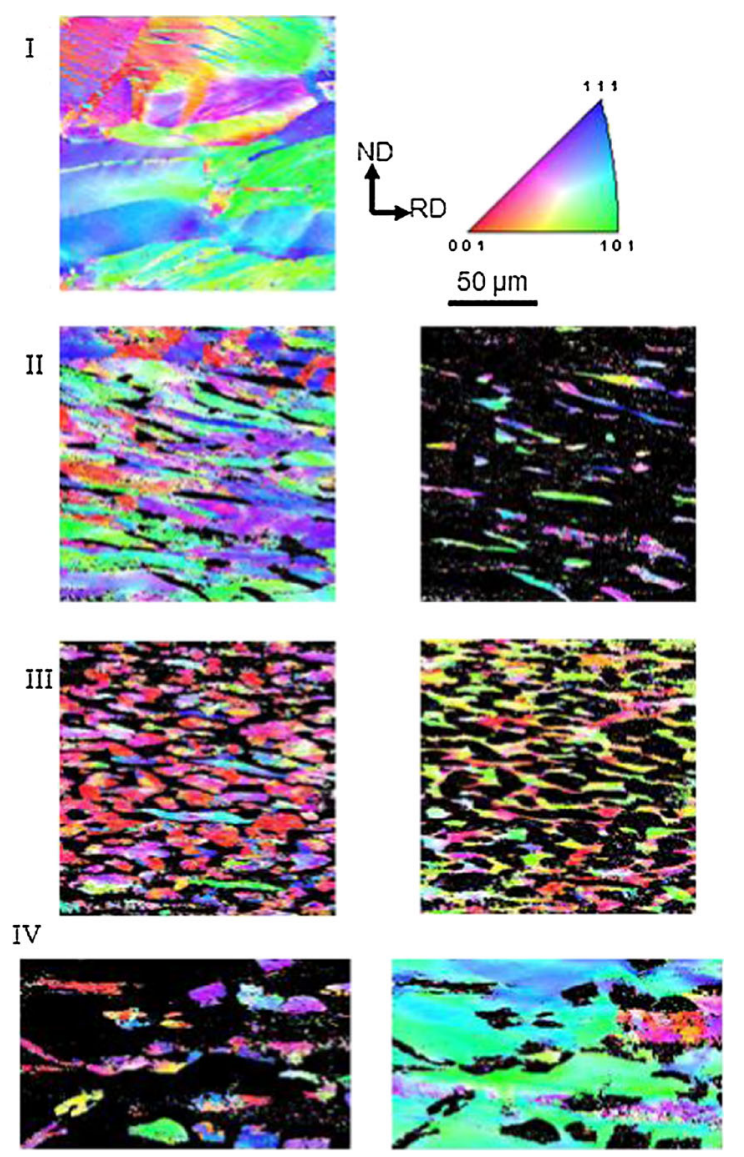

(a)

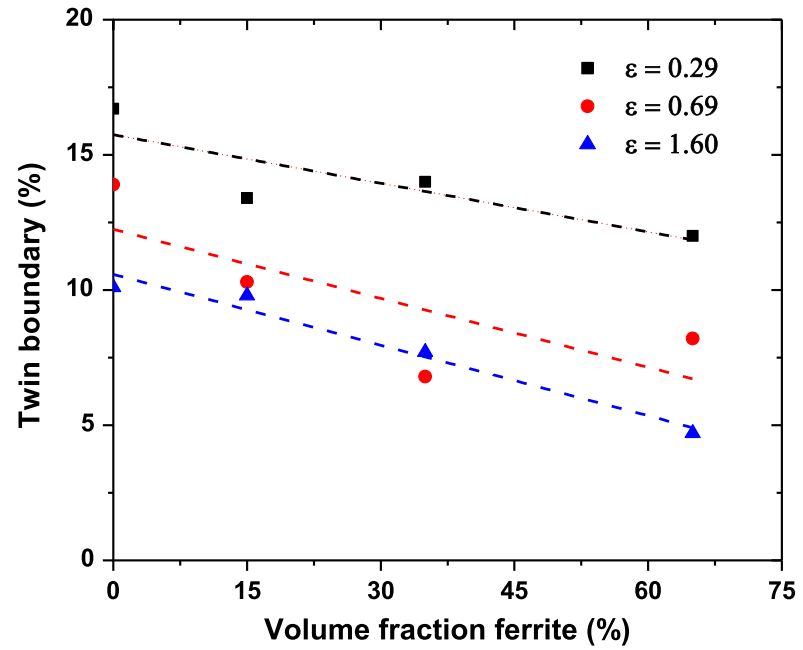

(b)
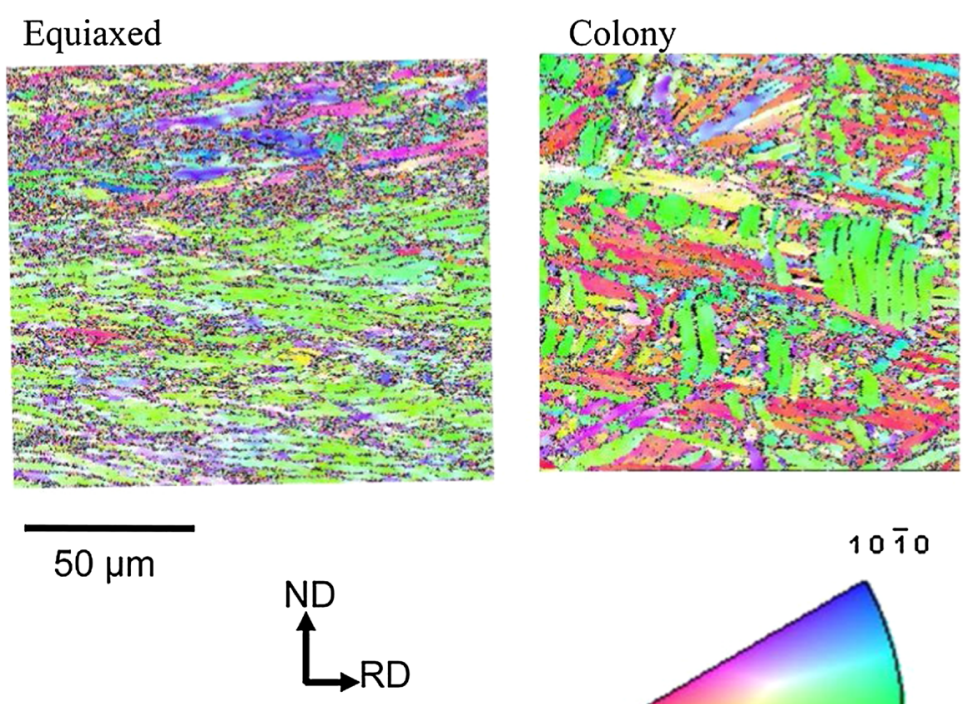

(c)

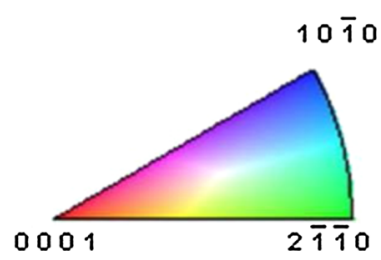

Fig. 7-(a) Inverse pole figure map of austenite (left) and ferrite phase (right) for Fe-Ni-Cr alloys rolled to strain 2.3 with $(b)$ twin fraction in terms of $\Sigma 3$ boundary fraction and $(c)$ inverse pole figure map for equiaxed and colony Ti-13Nb-13Zr sample deformed to strain $\varepsilon=1$ and 0.69 , respectively.

Table II. Evolution of Intragranular Misorientation Parameter Grain Average Misorientation (GAM ${ }^{\circ}$ ) in Fe-Ni-Cr Alloys with Deformation in Austenite and Ferrite Phases

\begin{tabular}{|c|c|c|c|c|c|c|c|c|}
\hline \multirow[b]{2}{*}{ Alloy } & \multicolumn{2}{|c|}{$\varepsilon=0.29$} & \multicolumn{2}{|c|}{$\varepsilon=0.69$} & \multicolumn{2}{|c|}{$\varepsilon=1.2$} & \multicolumn{2}{|c|}{$\varepsilon=2.3$} \\
\hline & Austenite & Ferrite & Austenite & Ferrite & Austenite & Ferrite & Austenite & Ferrite \\
\hline I & 1.6 & - & 2.0 & - & 2.0 & - & 2.1 & - \\
\hline II & 2.0 & 1.7 & 2.5 & 2.4 & 2.0 & 2.0 & 2.1 & 1.9 \\
\hline III & 2.4 & 2.5 & 2.6 & 2.6 & 2.0 & 2.1 & 2.2 & 2.1 \\
\hline IV & 1.8 & 1.8 & 2.2 & 2.2 & 2.1 & 2.1 & 2.1 & 2.2 \\
\hline
\end{tabular}

condition. Better understanding of such a phenomenon is obtained from crystal plasticity simulations which shed light on the detailed consequence and reasons of strain partitioning and are elaborated in the subsequent sections for $x \mathrm{Fe}-y \mathrm{Ni}-(100-x-y) \mathrm{Cr}$ alloys and different morphologies of Ti-13Nb-13Zr. 
Table III. Evolution of Intragranular Misorientation Parameter Grain Average Misorientation (GAM $\left.{ }^{\circ}\right)$ in $\alpha$ and $\beta$ Phases of Ti-13Nb-13Zr with Different Morphologies

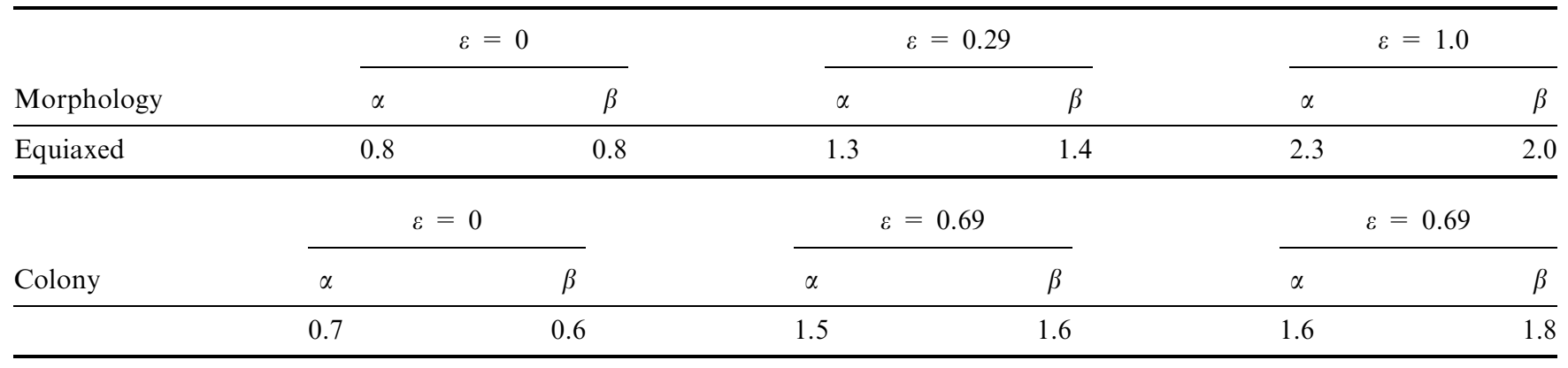
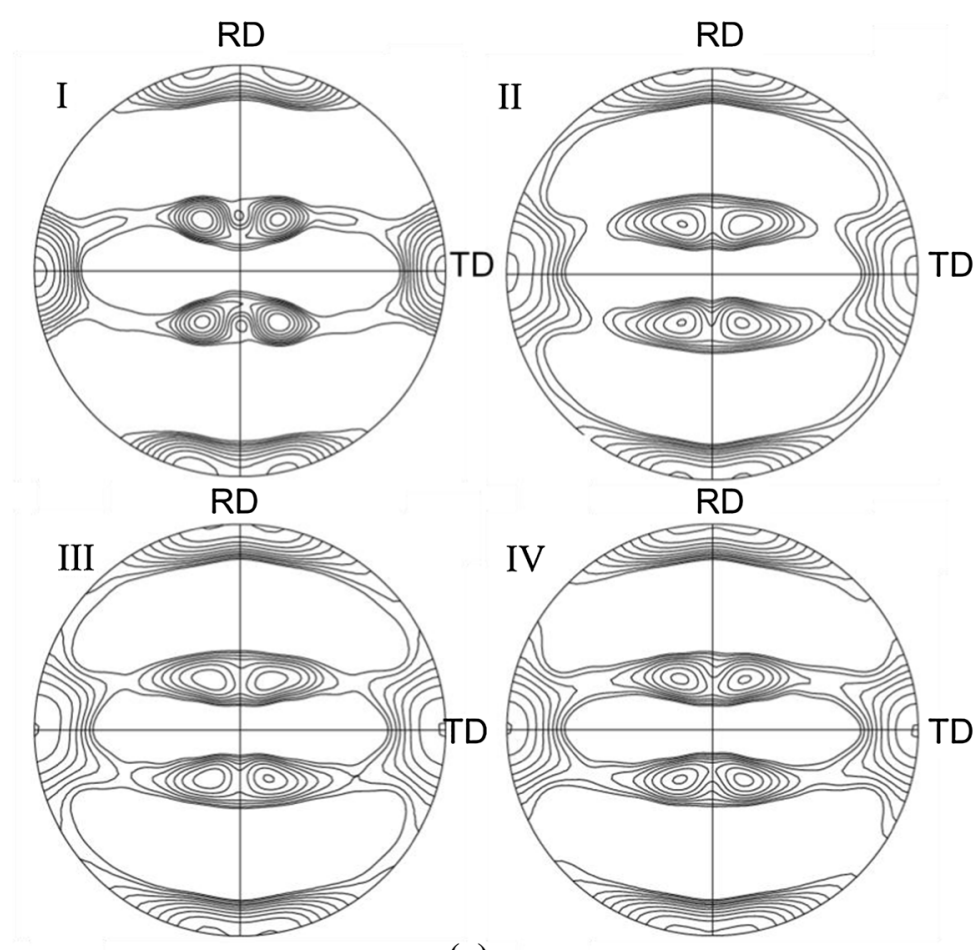

(a)

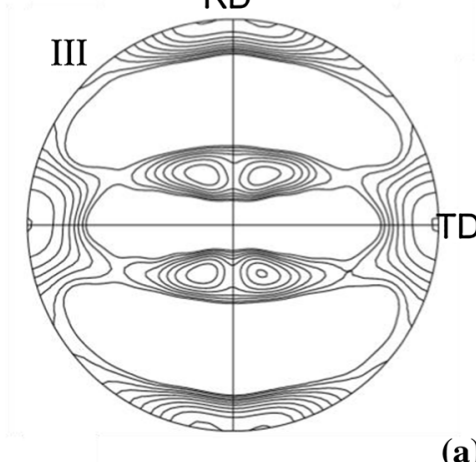

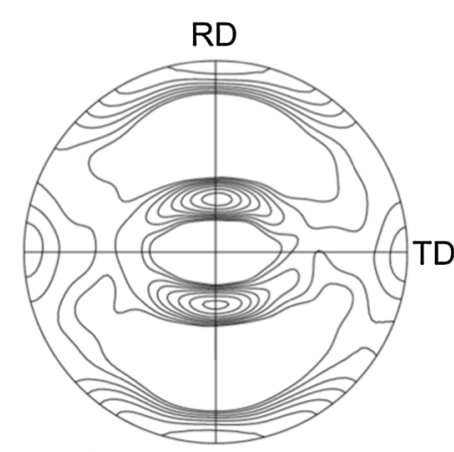

II

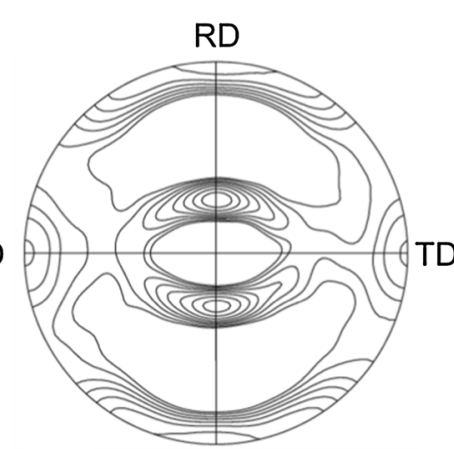

III

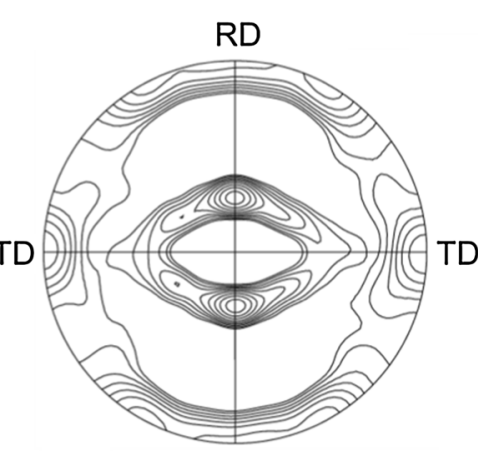

IV

(b)

Fig. 8- (a) 111 pole figures of the austenite phase $(b) 101$ pole figures of the ferrite phase for the four $\mathrm{Fe}-\mathrm{Ni}$-Cr alloys deformed to strain $\varepsilon=2.3$ and $(c) 0002$ pole figures of the $\alpha$ phase and $(d) 101$ pole figures of the $\beta$ phase in two morphologies of the Ti-13Nb-13Zr alloy for different simulation schemes. 

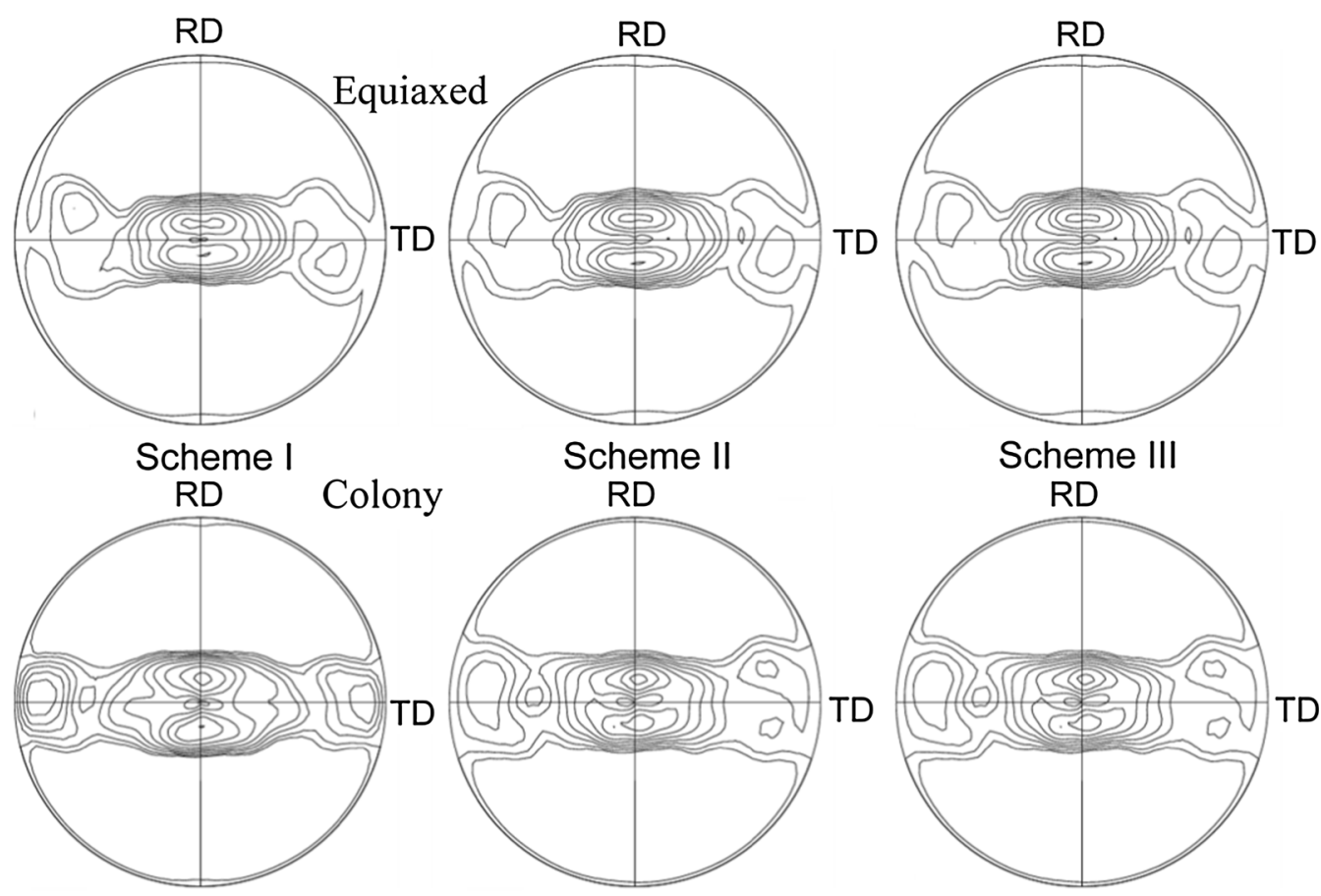

(c)
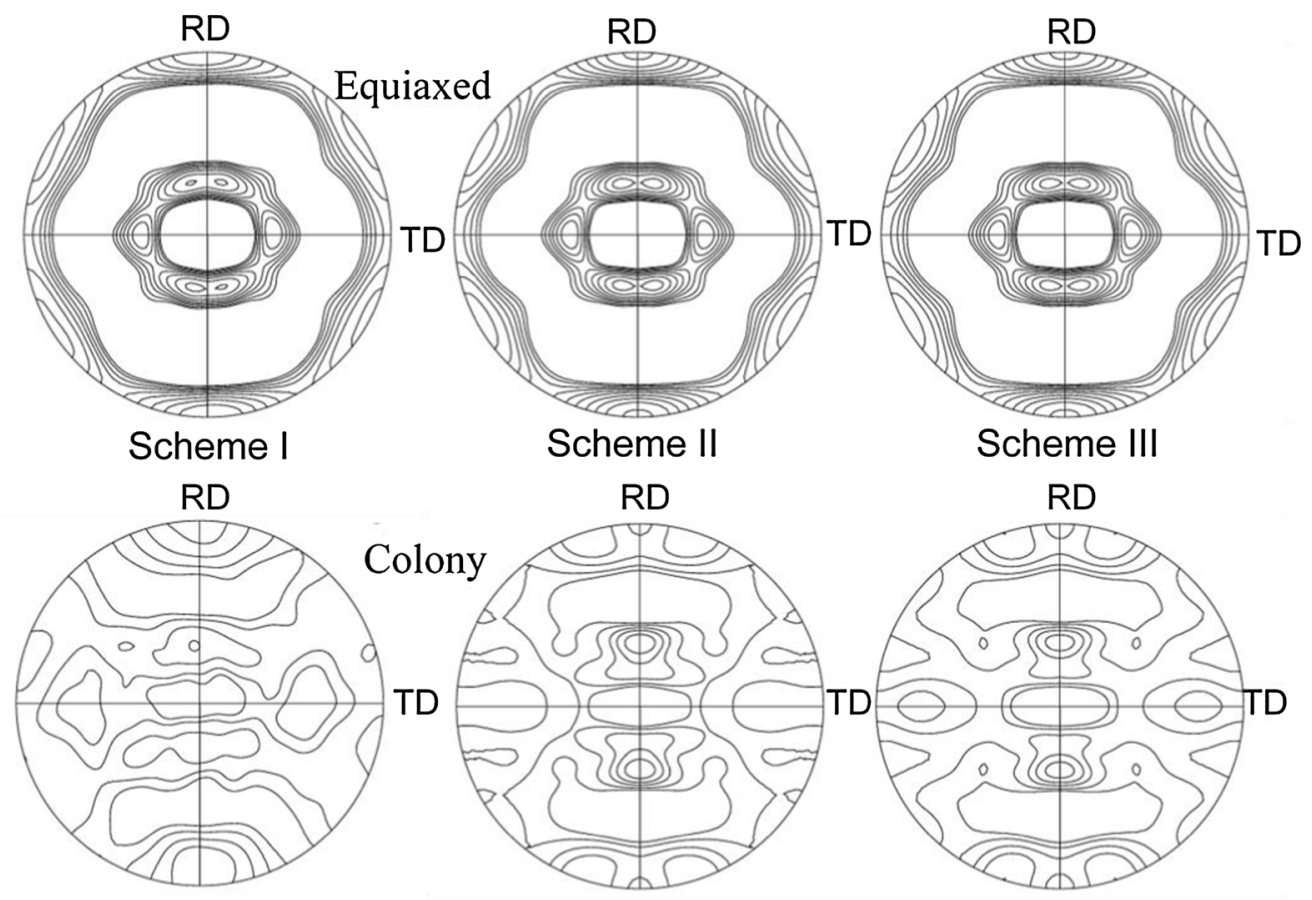

(d)

Fig. 8 - continued.

\section{B. Role of Volume Fraction and Contiguity}

There is a characteristic change in texture from Brass-type to Copper-type in the FCC austenite phase of Fe-Ni-Cr alloy. The evolution of Brass-type texture in low SFE FCC materials can be attributed to deformation twinning, shear banding, and planar slip. ${ }^{[43-49]}$ Leffers and Juul Jensen ${ }^{[50]}$ have shown that there is limited slip on the $\{111\}$ planes in grains undergoing twinning. This is tantamount to iso-stress Sachs model (single slip) unlike the iso-strain Taylor 
Table IV. Voce Hardening Parameters for Simulations for Austenite and Ferrite Phases of Fe-Ni-Cr Alloys

\begin{tabular}{lllll}
\hline Slip/Twin System & $\tau_{0}$ & $\tau_{1}$ & $\theta_{0}$ & $\theta_{1}$ \\
\hline$\{111\}\langle 110\rangle$ austenite & 35 & 38.3 & 65 & 2 \\
$\{111\}\langle 112\rangle$ twin austenite & 42.5 & 20 & 30 & 1.25 \\
$\{110\}\langle 111\rangle$ ferrite & 90 & 0 & 0 & 0 \\
\hline
\end{tabular}

Table V. Voce Hardening Parameters for Simulations of Ti-13Nb-13Zr Alloys

\begin{tabular}{lrrrr}
\hline Slip/Twin System & $\tau_{0}$ & $\tau_{1}$ & \multicolumn{1}{c}{$\theta_{0}$} & $\theta_{1}$ \\
\hline$\{0002\}\langle 1120\rangle \alpha$ prism & 45 & 40 & 1000 & 500 \\
$\{1010\}\langle 1120\rangle \alpha$ basal & 90 & 50 & 200 & 100 \\
$\{1011\}\langle 1123\rangle \alpha$ pyramidal & 395 & 10 & 2000 & 1100 \\
$\{110\}\langle 111\rangle \beta$ & 25 & 0 & 50 & 50 \\
\hline
\end{tabular}

Table VI. Different Simulation Schemes Opted in the Present Investigation

\begin{tabular}{|c|c|c|c|c|}
\hline & \multicolumn{2}{|c|}{$\begin{array}{c}\text { Aspect } \\
\text { Ratio }\end{array}$} & \multicolumn{2}{|c|}{ Morphological Orientation } \\
\hline & $\alpha$ & $\beta$ & $\alpha$ & $\beta$ \\
\hline Scheme (i) & yes & yes & no & no \\
\hline Scheme (ii) & yes & yes & yes $\left(\varphi_{1} \Phi \varphi_{2}\right)$ & yes $\left(\varphi_{1}^{*} \Phi^{*} \varphi_{2}^{*}\right)$ \\
\hline Scheme (iii) & yes & yes & yes $\left(\varphi_{1} \Phi \varphi_{2}\right)$ & yes $\left(\varphi_{1} \Phi \varphi_{2}\right)$ \\
\hline
\end{tabular}

model (multiple slip) in grains without twins. The inhomogeneous deformation can also lead to the formation of shear bands that can further contribute to Bs component. The formation of shear bands can erode the twinned microstructure, thereby leading to the reduction in the fraction of the twin-boundary fraction as observed in the present investigation. Nevertheless, a synergistic effect of twining by contributing to shear banding or planar slip is expected to lead to Brass-type texture in Fe-Ni-Cr alloy I. For the remaining alloys, the reduced propensity of twinning contributes to lower Bs component in the austenite phase.

A quantitative estimate of strain partitioning is obtained from simulations. There is an increase in the contribution to strain from the ferrite phase with increase in ferrite content in the two-phase $x \mathrm{Fe}-y \mathrm{Ni}-(100-x-y) \mathrm{Cr}$ alloys (Figure 9(a)) along with a qualitative match between experimental and simulated twin activity (Figure 9(b)). In addition, the ferrite phase carries more strain (Figure 9(c)) with increase in ferrite content but has lower number of average active slip systems than the austenite phase irrespective of the volume fraction of the ferrite phase. The continuous increase in the contribution to overall strain of the $\mathrm{BCC}$ ferrite phase indicates that the ferrite phase accommodated deformation and carried more strain with increasing ferrite content. Once the ferrite phase became contiguous, it carried majority of the strain despite of the higher hardness and showed stronger texture while the austenite phase showed the weakest texture despite showing a highly refined sub-structure. The grain reference orientation deviation map for alloy II and III samples deformed to strain of 0.29 shows higher misorientation in the percolating austenite and ferrite phases, respectively (Figure 10(a)). Propensity of twinning in the austenite phase is also compromised due to activation of slip in the harder ferrite phase. The exact reasons for the reduced twin activity will be discussed later. Thus, percolation plays an important role in strain partitioning compared to initial hardness and initial texture and determines the evolution of deformation microstructure and texture in two-phase ductile composites. The sub-structure evolution and texture evolution are decoupled for the non-contiguous soft austenite phase. A schematic depicting the effect of alpha phase on the micro-mechanisms of deformation of austenite phase is depicted in Figure 10(b) and will be discussed in a latter section.

\section{Role of Morphology of Individual Phases}

The effect of morphology on texture evolution in individual phases is not very drastic in $\mathrm{Ti}-13 \mathrm{Nb}-13 \mathrm{Zr}$ alloy compared to the effect of volume fraction of ferrite phase in Fe-Ni-Cr alloys. Simulation results indicate that during initial stages of deformation, the activity of $\{101\}\langle 111\rangle$ slip system in the $\beta$ phase is dominant, while $\alpha$ phase is deformed by prismatic and basal slip (Figure 11(a)). There was negligible activity of pyramidal slip for both the morphologies. The activity of basal slip became dominant over the prismatic slip in $\alpha$ phase during further deformation. Thus, another important observation was that the deformation in the $\alpha$ phase could be accommodated by the activation of only prismatic and basal slip systems without the activation of pyramidal slip system and extension or contraction twinning which are essential to accommodate strain along $c$-axis in HCP materials. The strain partitioning plot (Figure 11(b)) shows that the harder $\alpha$ phase carries higher strain at higher rolling reduction. This effect is more dominant for the colony microstructure and this can explain the lower ductility in colony microstructure compared to equiaxed microstructure. The number of average active slip systems in the hard HCP phase remains constant, while that in the $\mathrm{BCC}$ phase increases with strain (Figure 11(c)) indicating that the imposed strain is accommodated mostly in the softer phase. It is to be mentioned here that the extent of reorientation of both the phases during rolling is significantly different with the equiaxed morphology showing all the elongated grains aligned along rolling direction. However, this is not true for the colony morphology which leads to deviation from iso-stress condition that is observed for bamboo microstructure as shown in Figure 12.

\section{Effect of Second Phase on Micro-mechanisms of Deformation}

Experimental results clearly indicate that there is a change in operating micro-mechanisms in individual phase due to the presence of the other phase. The most striking is the reduction in twin activity in austenite phase of Fe-Ni-Cr alloys as well as the absence of extension twinning in $\alpha$ phase and increase in basal slip 


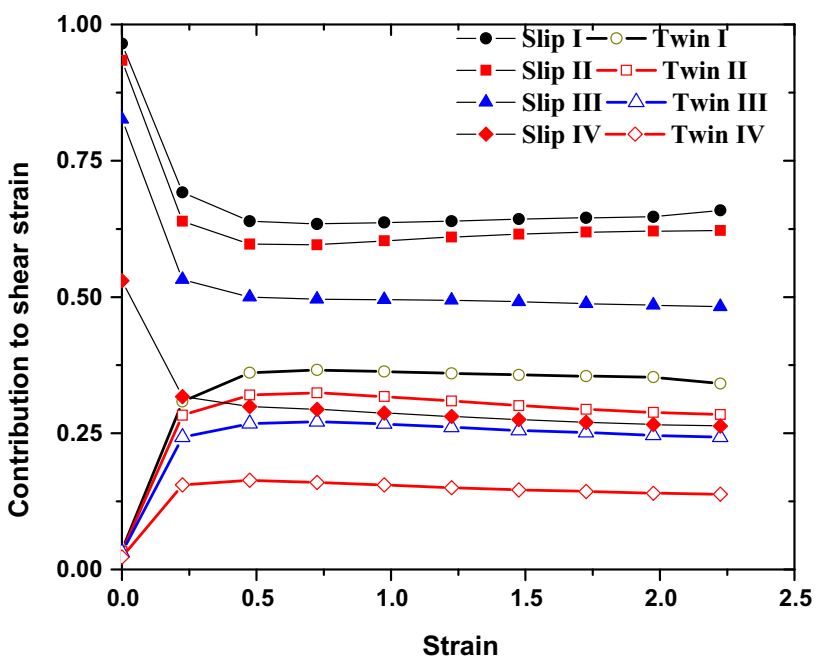

(a)

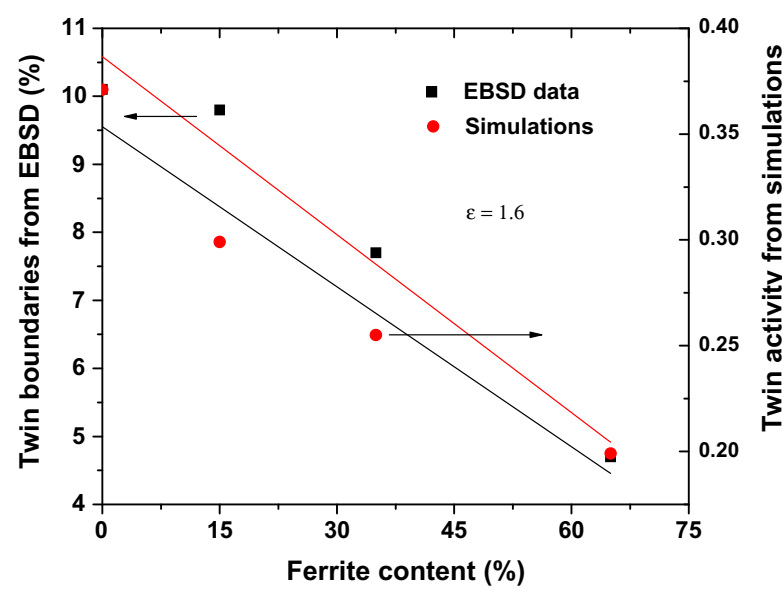

(b)

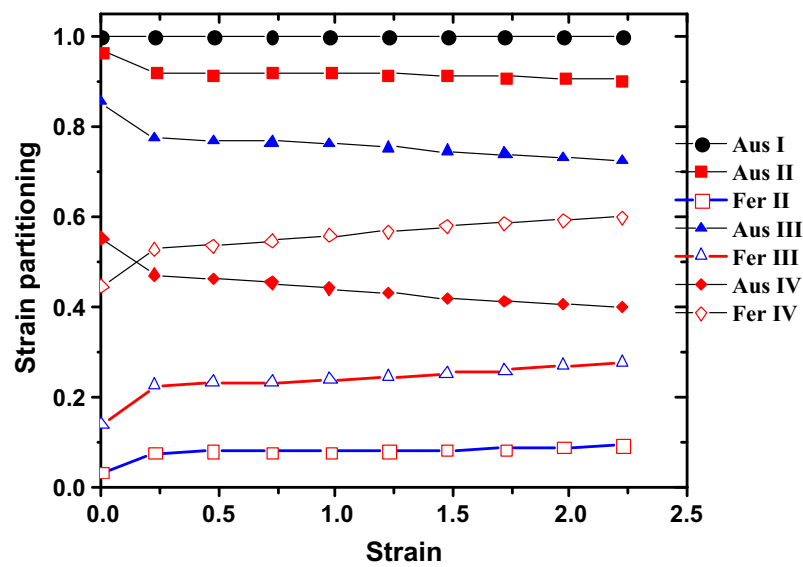

(c)

Fig. 9-(a) Activity of $\{111\}\langle 110\rangle$ slip system and $\{112\}\langle 110\rangle$ twin system in the austenite phase and $(b)$ comparison of twin activity from EBSD with simulations. (c) Strain partitioning in the austenite and ferrite phase for four different $\mathrm{Fe}-\mathrm{Ni}$-Cr alloys.

of Ti-13Nb-13Zr alloy. The effect of various material variables like purity, grain size, strain rate, temperature, and pre-strain is well understood. ${ }^{[51]}$ However, the effect of second phase on the propensity of twinning is not well understood. It has been reported that aging in $\mathrm{Ti}-\mathrm{Zr}$ alloys leads to suppression of twinning. This is attributed to the difficulty in propagating a twin across a coherent or incoherent boundary. In addition, the complex dislocation structure that is expected to evolve during the deformation of a composite could also lead to suppression of twinning. Twinning involves co-operative movement of partial dislocations on parallel planes that may be hindered in the presence of the second phase as the major criterion is to maintain cohesion between the two phases. It is also known that twin nucleation can be either homogenous or defect assisted. In most cases, twinning is defect assisted and homogenous twin occurs only in perfect crystals. However, the stress required to nucleate a twin is quite high compared to the stress required for twin propagation. It is well known that in single-phase materials, the localized value of stress at triple junction or grain boundary may exceed the stress required to nucleate a twin. However, in case of two-phase composites, the localized stresses may lead to propagation of slip in the second phase if the CRSS of the slip system of the second phase is lower than the nucleation stress for twinning in the first phase. It can be easily understood that with increase in fraction of ferrite content, the higher probability of heterogeneous interfaces can contribute in reducing twin nucleation in the austenite phase drastically. A schematic depicting such a scenario is presented in Figure 10(b). The operation of twinning in the austenite phase is governed by not only the critical resolved stress for twinning and the resolved shear stress but also the resolved shear stress in the ferrite phase. The continuous decrease in twinning activity with increase in ferrite content indicates that there is an increase in the activity of slip in ferrite at the expense of twinning in austenite.

Similar argument can be proposed for Ti-13Nb-13Zr alloy for suppression of extension and contraction twinning as well as pyramidal $\langle c+a\rangle$ slip; however, morphology also plays a role in suppressing twinning. The interaction stress is expected to be higher for the lamellar microstructure, but the smaller size of $\alpha$ grains/ lamellas ensures that the twin propensity is reduced. Therefore, twinning is not observed in $\alpha$ phase of Ti-13Nb-13Zr alloy irrespective of the different morphology and volume fraction of the $\beta$ phase. Another important observation is that the activity of pyramidal $\langle c+a\rangle$ is suppressed in $\alpha$ phase of Ti-13Nb-13Zr alloy in the presence of $\beta$ phase. It is to be mentioned here that in the absence of extension and contraction twinning, $\langle c+a\rangle$ pyramidal slip is the only mechanism that can accommodate strain along $c$-axis of the HCP $\alpha$ phase. The higher stress concentration for the colony sample explains the reduced formability of the sample with respect to the equiaxed microstructure.

An important observation from viscoplastic self-consistent simulations is that strain partitioning between the phases is accompanied with significant difference in number of active slip systems in the two phases. The softer phase not only carries more strain but also has more slip systems active than the harder phase. Thus, the von Mises criterion of having five independent shear 

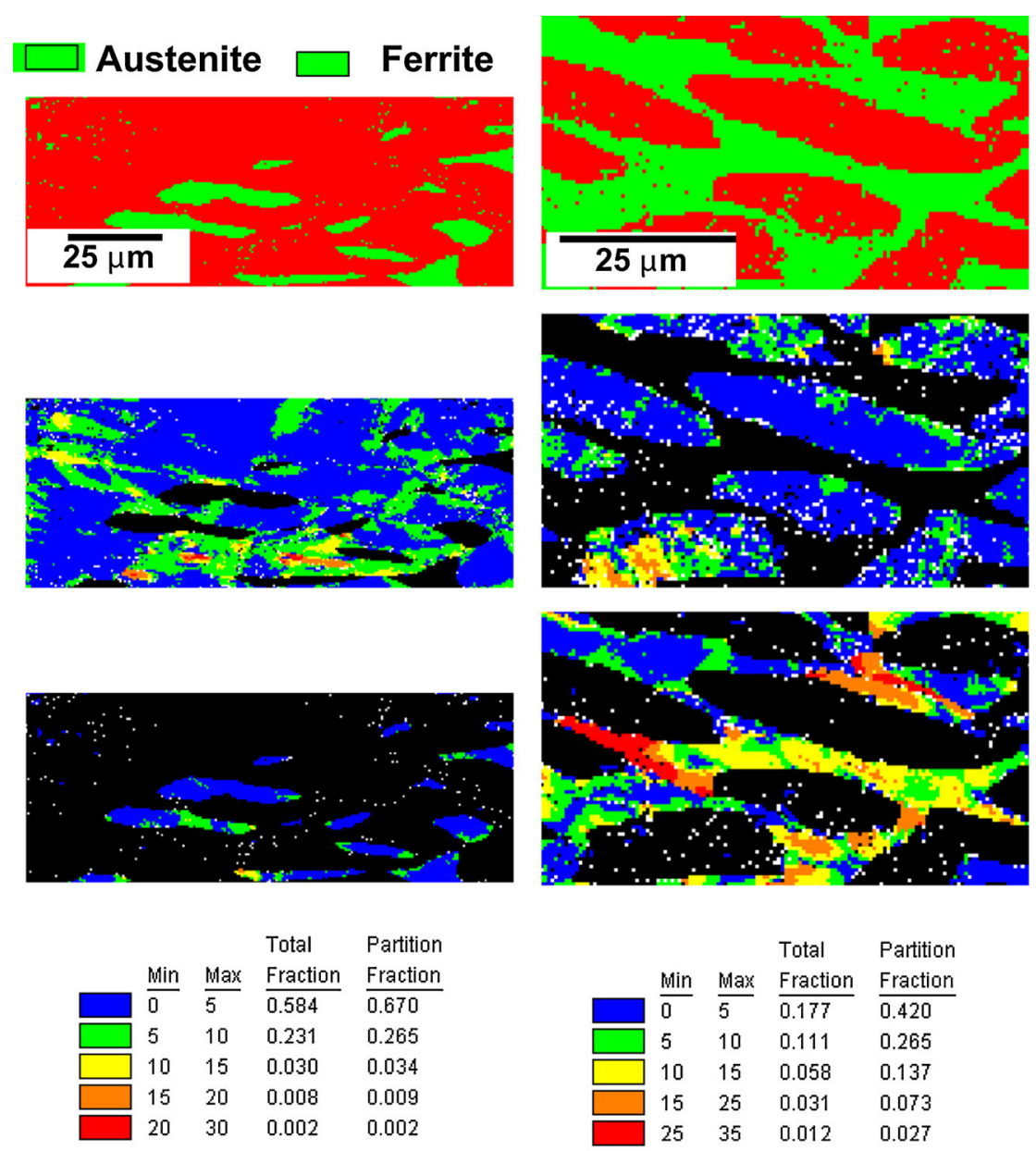

(a)

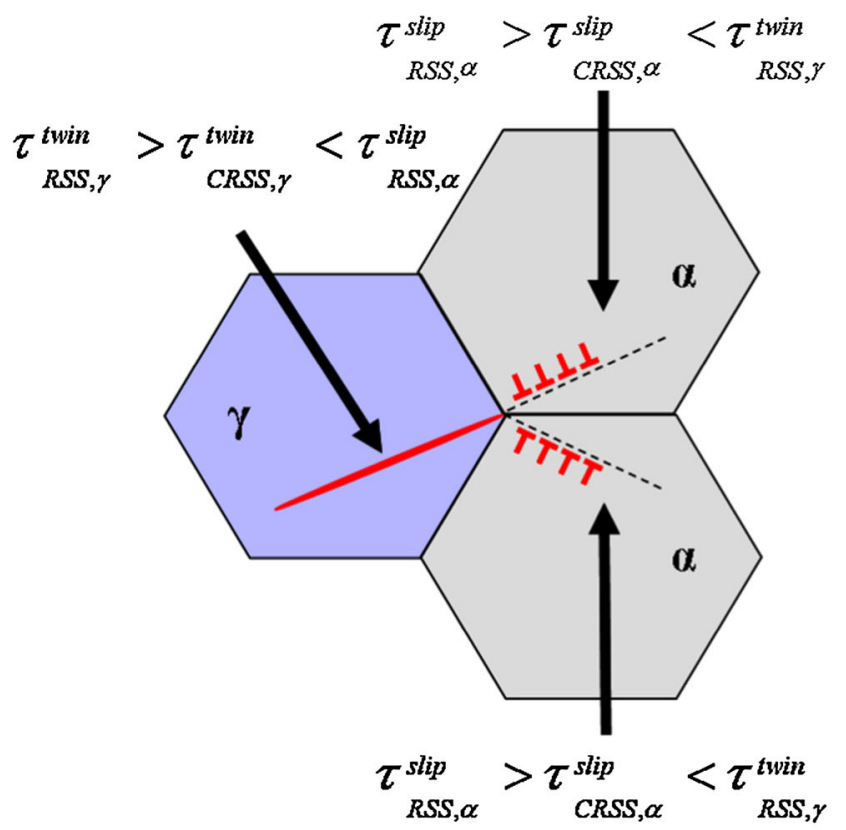

(b)

Fig. 10 - (a) Grain reference orientation deviation maps in alloy II (left) and alloy III (right) deformed to strain of 0.29 show higher misorientation in the contiguous austenite phase and ferrite phase, respectively. (b) Schematic showing the possible operative micro-mechanisms in twophase austenite-ferrite alloy. 

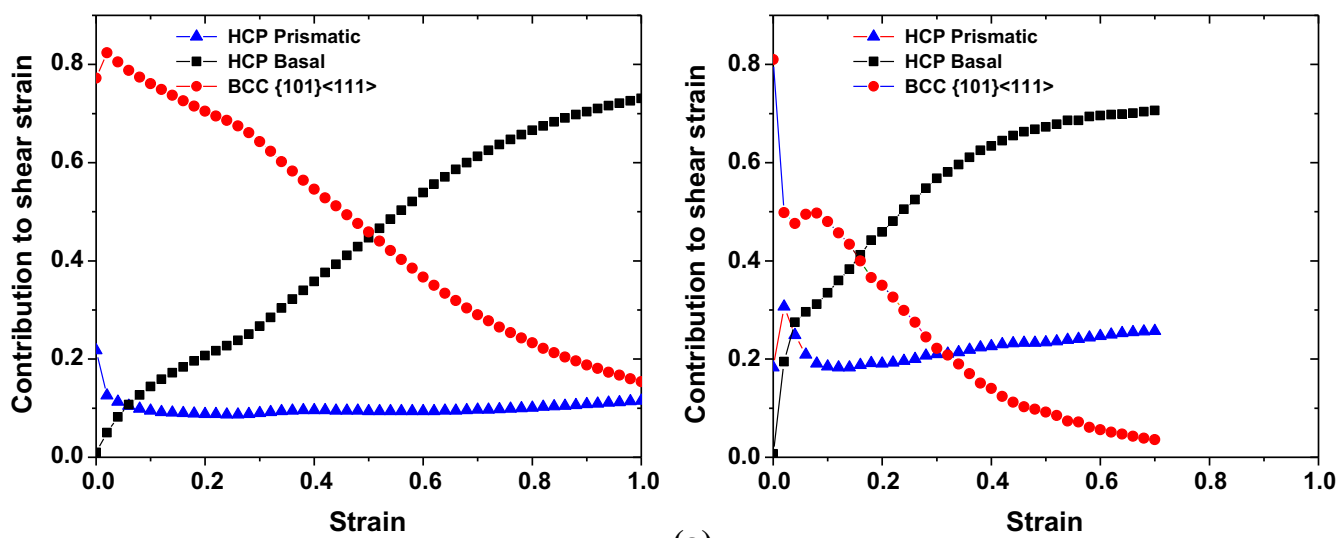

(a)
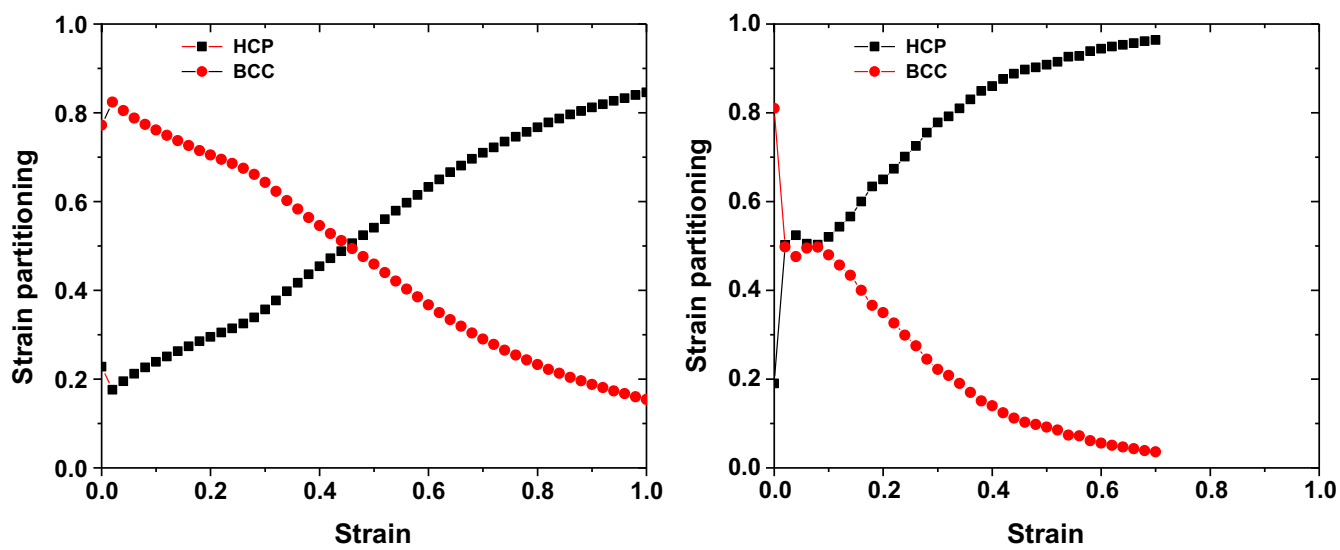

(b)
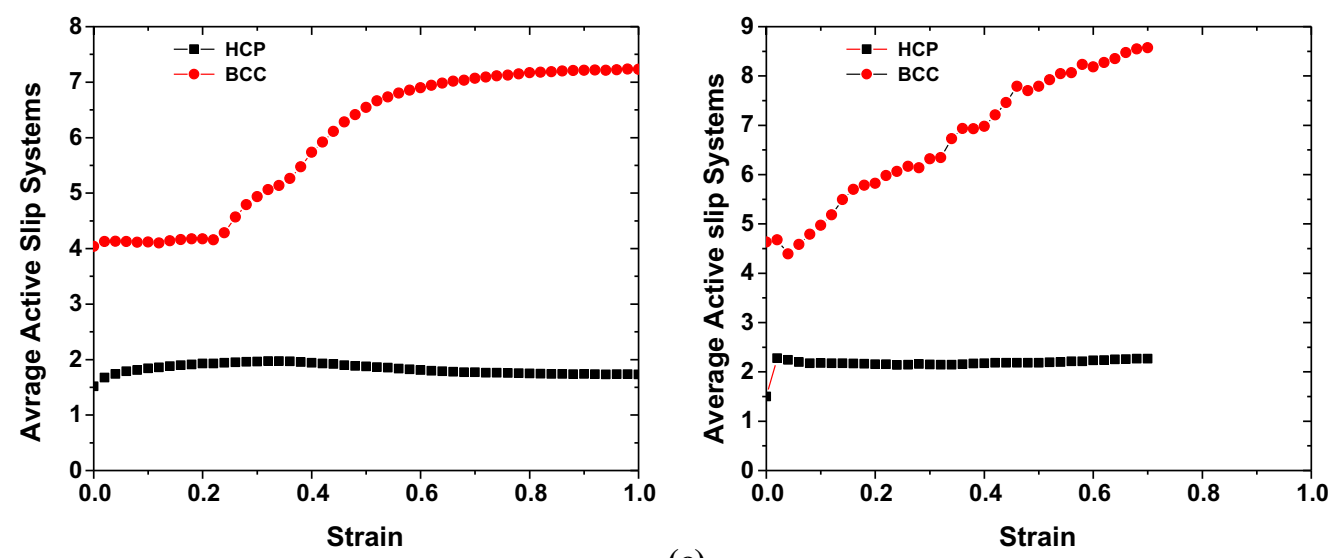

(c)

Fig. 11-(a) Slip activity, (b) strain partitioning and (c) average active slip systems in HCP $\alpha$ and BCC $\beta$ phase in Ti-13Nb-13Zr alloy for equiaxed (left) and colony (right) morphology.

(slip/twinning) systems which is pre-requisite for the Taylor iso-strain approximation is not valid for two-phase deformation. From a mechanistic point of view, classical iso-strain Taylor approximation and the lower bound iso-stress Sachs approximation constitute the two extremes of polycrystal deformation in single-phase materials. It is also agreed that most materials follow the Taylor approximation either strictly or in a relaxed way at large strain. The aforementioned criterion is very stringent and viscoplastic self-consistent simulation imposes the same in an average way. However, the presence of second phase puts a stringent criterion for the validity of the iso-strain approximation due to drastically different elasto-plastic properties of the individual phases at low strain. In case of ductile two-phase systems, it appears that the softer phase compensates for the lack of sufficient shear systems (slip or twining) in the harder phase. Similar situation is encountered during deformation of a polycrystal with high aspect ratio of both the phases at a lower strain 

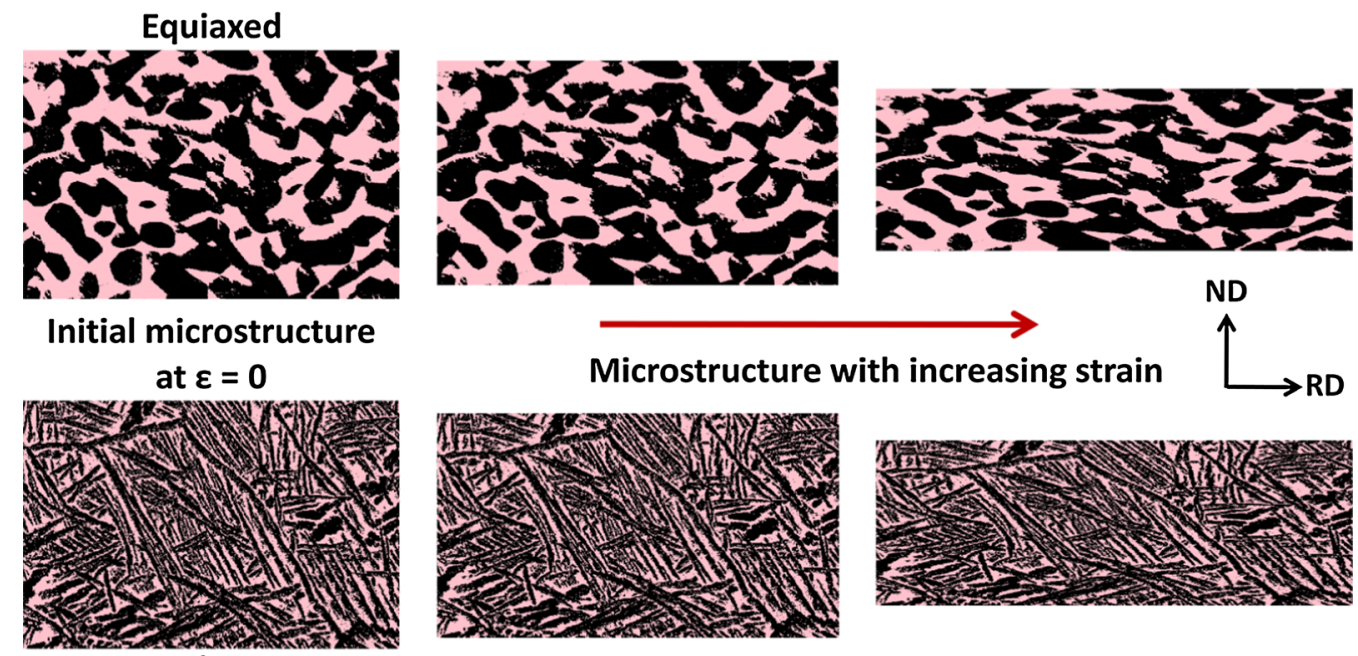

ND

Colony

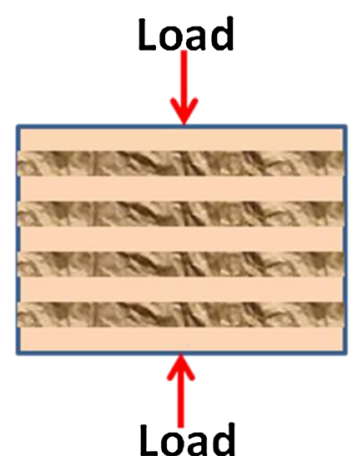

Fig. 12-Schematic showing evolution of microstructure for different morphologies. Equiaxed morphology shows both the phases oriented to direction of rolling, while the extent of reorientation is not complete for colony microstructure. Microstructure in equiaxed phase promotes iso-stress condition, while that in colony is not suitable for iso-stress condition. This explains higher ductility of equiaxed morphology compared to colony morphology in Ti-13Nb-13Zr.

compared to a polycrystal with equiaxed phase morphology. Thus, higher volume fraction of second phase or higher aspect ratio of individual phase can lead to a deviation from iso-strain condition which demands minimum five independent slip systems. Therefore, it can be concluded that iso-stress condition in individual phases is favored during two-phase deformation at large strain.

\section{SUMMARY AND CONCLUSIONS}

In the present investigation, a series of $x \mathrm{Fe}-y$ $\mathrm{Ni}-(100-x-y) \mathrm{Cr}$ alloys and $\mathrm{Ti}-13 \mathrm{Nb}-13 \mathrm{Zr}$ were used as a model system to study the evolution of deformation texture and sub-structure in the individual phases of FCC-BCC and HCP-BCC two-phase materials, respectively, as a function of contiguity and morphology. A combinatorial approach comprising of state-of-the-art experimental techniques and crystal plasticity simulations was used to understand deformation behavior of two-phase systems. The major findings of the present investigation are as follows:
1. In $x \mathrm{Fe}-y \mathrm{Ni}-(100-x-y) \mathrm{Cr}$ alloys, an increase in the volume fraction of the harder BCC ferrite phase led to transition of deformation micro-mechanism from contiguous austenite to ferrite phase. It is found that contiguity leads to strain partitioning in the phases, which affects the operative micro-mechanisms in individual phases. This leads to decrease in twinning in the FCC austenite phase which contributed to weakening of Bs component in the austenite phase with increasing ferrite content. On the contrary, texture in $\mathrm{BCC}$ ferrite phase became stronger with increased contiguity of the ferrite phase.

2. The effect of morphology in Ti-13Nb-13Zr alloys is more subdued as there is no characteristic change in texture with change in morphology. However, the strength of texture evolution in individual phases is altered with the colony morphology showing weaker texture for the softer beta phase.

3. Viscoplastic self-consistent simulations were able to correctly predict texture and microstructural features in terms of twin and slip activity in individual phases of two-phase alloys. A quantitative estimate 
of strain partitioning due to contiguity and morphology which affects deformation micro-mechanisms is successfully achieved using simulations.

4. Deformation behavior of two-phase aggregates at higher strain is closer to the lower bound Sachs approximation than the upper bound Taylor approximation. The transition from Taylor- to Sachs-type behavior is aided by increasing volume fraction of the second phase and higher aspect ratio of individual phases in two-phase alloys.

\section{ACKNOWLEDGMENTS}

The authors would like to acknowledge Dr. S. K. Bhaumik of National Aeronautical Laboratory, Bangalore, India, for providing the assistance in melting the alloys used in the present study. The authors are grateful to Dr. C. N. Tome and Dr. R. A. Lebensohn (Los Alamos National Laboratory, USA) for providing VPSC-7 code. NPG had useful discussions with Dr. K. S. Suresh. The authors thank the Department of Science and Technology, Government of India, for providing characterization facilities at the Institute X-ray facility and Advanced Facility for Microscopy and Microanalysis at Indian Institute of Science, Bangalore, India.

\section{REFERENCES}

1. U.F. Kocks, C.N. Tome, and H.-R. Wenk: Texture and Anisotropy, Cambridge University Press, Cambridge, 1998, pp. 178-208.

2. Y. Tamota, K. Kuroki, T. Mori, and I. Tamura: Mater. Sci. Eng., 1976, vol. 24, pp. 85-94.

3. K. Morii, H. Mecking, G. Lutjering, and Y. Nakayama: Scripta Metall., 1986, vol. 20, pp. 1795-800.

4. S. Ankem and H. Margolin: Metall. Trans. A, 1986, vol. 17, pp. 2209-26.

5. S. Ankem, H. Margolin, C.A. Greene, B.W. Neuberger, and P.G. Oberson: Prog. Mater. Sci., 2006, vol. 51, pp. 632-709.

6. D. Mattisen, D. Raabe, and F. Heringhaus: Acta Mater., 1999, vol. 47, pp. 1627-34.

7. J. Wang and A. Misra: Curr. Opin. Solid State Mater. Sci., 2011, vol. 15 , pp. $20-28$.

8. J.J. Moverare and M. Oden: Metall. Mater. Trans. A, 2002, vol. 33A, pp. 57-71.

9. C. Mapelli, S. Barella, and R. Venturin: ISIJ Int., 2005, vol. 45, pp. 1727-35.

10. N. Jia, R.L. Peng, Y.D. Wang, S. Johansson, and P.K. Liaw: Acta Mater., 2008, vol. 56, pp. 782-93.

11. H. Inoue, S. Fukwshima, and N. Inakazu: Mater. Trans. JIM, 1992, vol. 33, pp. 129-37.

12. N. Gey, M. Humbert, M.J. Phillip, and Y. Combres: Mater. Sci. Eng. A, 1996, vol. 219, pp. 80-88.

13. S. Suwas and R.K. Ray: Metall. Mater. Trans. A, 2000, vol. 31A, pp. 2339-50.

14. S. Suwas, R.K. Ray, A.K. Singh, and S. Bhargava: Acta Mater., 1999, vol. 47, pp. 4585-98.

15. H.-G. Brokmeier: Mater. Sci. Eng. A, 1994, vol. 175, pp. 131-39.

16. R.A. Lebensohn and G.R. Canova: Acta Mater., 1997, vol. 45, pp. 3687-94.
17. H.-G. Brokmeier, R.E. Bolmaro, J.A. Signorelli, and A. Fourty: Phys. B, 2000, vols. 276-278, pp. 888-89.

18. B. Commentz, C. Hartig, and H. Mecking: Comput. Mater. Sci., 1999, vol. 16, pp. 237-47.

19. C. Hartig and H. Mecking: Comput. Mater. Sci., 2005, vol. 32, pp. 370-77.

20. Y. Schneider, A. Bertram, T. Bohlke, and C. Hartig: Comput. Mater. Sci., 2010, vol. 48, pp. 456-65.

21. R.E. Bolmaro, A. Fourty, J.W. Signorelli, and H.-G. Brokmeier: Model. SimuMater. Sci. Eng., 2006, vol. 14, pp. 1-20.

22. C.W. Sinclair, J.D. Embury, G.C. Weatherly, K.T. Conlon, and O. Engler: Mater. Sci. Technol., 2003, vol. 19, pp. 1321-29.

23. M. Kiran Kumar, I. Samajdar, N. Venkatramani, G.K. Dey, R. Tewari, D. Srivastava, and S. Banerjee: Acta Mater., 2003, vol. 51, pp. 625-40.

24. J.L.W. Warwick, J. Coakley, S.L. Raghunathan, R.J. Talling, and D. Dye: Acta Mater., 2012, vol. 60, pp. 4117-27.

25. J. Kadkhodapour, S. Schmauder, D. Raabe, S. Ziaei-Rad, U. Weber, and M. Calcaguotto: Acta Mater., 2011, vol. 59, pp. 4387-94.

26. R. Garg, S. Ranganathan, and S. Suwas: Mater. Sci. Eng. A, 2010, vol. 527, pp. 4582-92.

27. D. Raabe, K. Mivake, and H. Takahara: Mater. Sci. Eng. A, 2009, vol. 291, pp. 186-97.

28. D. Raabe, S. Ohsaki, and K. Hono: Acta Mater., 2009, vol. 57, pp. $5254-63$

29. N. Jia, F. Roters, P. Eisenlohr, D. Raabe, and X. Zhao: Acta Mater., 2013, vol. 61, pp. 4591-606.

30. J. Wang, I.J. Beyerlein, N.A. Mara, and D. Bhattacharyya: Scripta Mater., 2001, vol. 64, pp. 1083-86.

31. P.M. Anderson, J.F. Bingert, A. Misra, and J.P. Hirth: Acta Mater., 2003, vol. 51, pp. 6059-75.

32. A. Misra, J.P. Hirth, R.G. Hoagland, J.D. Embury, and H. Kung: Acta Mater., 2004, vol. 52, pp. 2387-94.

33. A. Misra, J.P. Hirth, and R.G. Hoagland: Acta Mater., 2006, vol. 53, pp. 4817-24.

34. I.J. Beyerlein, N.A. Mara, D. Bhattacharyya, D.J. Alexander, and C.T. Necker: Int. J. Plast., 2011, vol. 27, pp. 121-46.

35. I.J. Beyerlein, J.R. Mayeur, S. Zheng, N.A. Mara, J. Wang, and A. Misra: Proc. Natl. Acad. Sci., 2014, vol. 111, pp. 4386-90.

36. C.C. Tasan, J.P.M. Hoefnagels, M. Diehl, D. Yan, F. Roters, and D. Raabe: Int. J. Plast., 2014, vol. 63, pp. 198-210.

37. K. Pawlik: Phys. Stat. Sol. B, 1986, vol. 134, pp. 477-83.

38. C.N. Tomè, G.R. Canova, U.F. Kocks, N. Christodoulou, and J.J. Jonas: Acta Metall., 1984, vol. 32, pp. 1637-53.

39. R.A. Lebensohn and C.N. Tomè: Acta Metall. Mater., 1993, vol. 41, pp. 2611-24.

40. R.A. Lebensohn and G.R. Canova: Acta Mater., 1997, vol. 45, pp. 3687-94.

41. G. Kurdjumov and G. Sachs: Zeitschridft fuer Physik, 1930, vol. 64 , pp. 325-43.

42. W.G. Burgers: Physica, 1934, vol. 1, pp. 561-86.

43. G. Wasserman: Z. Metall., 1963, vol. 54, pp. 61-65.

44. T. Leffers and A. Grum-Jensen: Trans. Metall. Soc. AIME, 1968, vol. 242, pp. 314-19.

45. O. Engler: Acta Mater., 2000, vol. 48, pp. 4827-40.

46. E. El-Danaf, S.R. Kalidindi, R.D. Doherty, and C. Necker: Acta Mater., 2002, vol. 48, pp. 2665-73.

47. T. Leffers and R.K. Ray: Prog. Mater. Sci., 2009, vol. 54, pp. $351-96$.

48. C. Donadille, R. Valle, P. Dervin, and R. Penelle: Acta Metall., 1989, vol. 37 , pp. $1547-71$.

49. C.D. Singh, V. Ramaswamy, and C. Suryanarayana: Textures Microstruct., 1992, vol. 9, pp. 101-21.

50. T. Leffers, D. Juul Jensen: Proc. Inter. Conf. on Texture of Materials-7, Netherlands Society for Materials Science, Zwijndrecht, 1984, pp. 805-10.

51. J.W. Christian and S. Mahajan: Prog. Mater. Sci., 1995, vol. 39, pp. 1-157. 